\title{
SciencesPo
}

\section{The Transmission of Monetary Policy Shocks}

Silvia Miranda-Agrippino

Giovanni Ricco 
EDITORIAL BOARD

Chair: Xavier Ragot (Sciences Po, OFCE)

Members: Jérôme Creel (Sciences Po, OFCE), Eric Heyer (Sciences Po, OFCE), Lionel Nesta (Université Nice Sophia Antipolis), Xavier Timbeau (Sciences Po, OFCE)

\title{
CONTACT US
}

OFCE

10 place de Catalogne | 75014 Paris | France

Tél. +33144185487

www.ofce.fr

\author{
WORKING PAPER CITATION
}

This Working Paper:

Silvia Miranda-Agrippino, Giovanni Ricco, The Transmission of Monetary Policy Shocks, Sciences Po OFCE Working Paper, $n^{\circ} 15,2017-05-05$.

Downloaded from URL : www.ofce.sciences-po.fr/pdf/dtravail/WP2017-15.pdf DOI - ISSN 


\title{
ABOUT THE AUTHORS
}

Silvia Miranda-Agrippino Bank of England, United Kingdom and CFM

Email Address: silvia.miranda-agrippino@bankofengland.co.uk

Giovanni Ricco University of Warwick, United Kingdom and OFCE, Sciences Po Paris, France Email Address: G.Ricco@warwick.ac.uk

\begin{abstract}
Despite years of research, there is still uncertainty around the effects of monetary policy shocks. We reassess the empirical evidence by combining a new identification that accounts for informational rigidities, with a flexible econometric method robust to misspecifications that bridges between VARs and Local Projections. We show that most of the lack of robustness of the results in the extant literature is due to compounding unrealistic assumptions of full information with the use of severely misspecified models. Using our novel methodology, we find that a monetary tightening is unequivocally contractionary, with no evidence of either price or output puzzles.
\end{abstract}

\section{KEY WORDS}

Monetary Policy, Local Projections, VARs, Expectations, Information Rigidity, Survey Forecasts, External Instruments.

\section{JEL}

C11; C14; E52; G14. 


\section{ABOUT OFCE}

The Paris-based Observatoire français des conjonctures économiques (OFCE), or French Economic Observatory is an independent and publicly-funded centre whose activities focus on economic research, forecasting and the evaluation of public policy.

Its 1981 founding charter established it as part of the French Fondation nationale des sciences politiques (Sciences Po), and gave it the mission is to "ensure that the fruits of scientific rigour and academic independence serve the public debate about the economy". The OFCE fulfils this mission by conducting theoretical and empirical studies, taking part in international scientific networks, and assuring a regular presence in the media through close cooperation with the French and European public authorities. The work of the OFCE covers most fields of economic analysis, from macroeconomics, growth, social welfare programmes, taxation and employment policy to sustainable development, competition, innovation and regulatory affairs..

\section{ABOUT SCIENCES PO}

Sciences $\mathrm{Po}$ is an institution of higher education and research in the humanities and social sciences. Its work in law, economics, history, political science and sociology is pursued through ten research units and several crosscutting programmes.

Its research community includes over two hundred twenty members and three hundred fifty PhD candidates. Recognized internationally, their work covers a wide range of topics including education, democracies, urban development, globalization and public health.

One of Sciences Po's key objectives is to make a significant contribution to methodological, epistemological and theoretical advances in the humanities and social sciences. Sciences Po's mission is also to share the results of its research with the international research community, students, and more broadly, society as a whole. 


\section{The Transmission of Monetary Policy Shocks}

We are grateful to Refet Gürkaynak for sharing the updated daily US monetary surprises. We thank Gianni Amisano, Philippe Andrade, Matteo Barigozzi, Dario Caldara, Fabio Canova, Matteo Ciccarelli, James Cloyne, Jérôme Creel, Cristina Fuentes-Albero, Raffaella Giacomini, Domenico Giannone, Refet Gürkaynak, James Hamilton, Edward Herbst, Paul Hubert, Marek Jarociński, Oscar Jordà, Alejandro Justiniano, Peter Karadi, Dimitris Korobilis, Ulrich Müller, Michael Pitt, Ricardo Reis, Giuseppe Ragusa, Francesco Ravazzolo, Lucrezia Reichlin, Frank Schorfheide, James Stock, seminars and conference participants at the OFCE/Science-Po EME 2015 Workshop, the 2015 DIW Macroeconometric Workshop, the NBER SBIES 2016, the ECB Workshop on New Techniques and Applications of BVARs 2016, AMES and LAMES 2016, the 2016 Real-Time Data Analysis Methods and Applications Conference, ESOBE 2016, ULB, EUI, Norges Bank, and Banca d'Italia for helpful comments and suggestions. The views expressed in this paper are those of the authors and do not necessarily reflect those of the Bank of England, the Monetary Policy Committee, the Financial Policy Committee or the Prudential Regulation Authority. 


\section{Introduction}

There is still a lot of uncertainty around the effects of monetary policy, despite fifty years of empirical research, and many methodological advances. ${ }^{1}$ The dynamic responses of macroeconomic variables that are reported in the literature are often controversial and, under close scrutiny, lack robustness (see Ramey, 2016). Not just the magnitude and the significance, but even the sign of the responses of crucial variables such as output and prices depend on the identification strategy, the sample period, the information set considered, and the details of the model specification.

Studying the effects of monetary policy is a difficult endeavour. Most of the variation in monetary aggregates is accounted for by the way in which policy itself responds to the state of the economy, and not by random disturbances to the central bank's reaction function. Hence, to be able to trace causal effects of monetary policy it is necessary $(i)$ to isolate unexpected exogenous shifts to monetary policy tools that are not due to the systematic response of policy to either current or forecast economic conditions (Sims, 1992, 1998), and (ii) to generate responses of macroeconomic and financial variables over time using an econometric model that is effectively capable of summarising the dynamic interaction among such variables. The empirical practice has typically relied on several identification schemes all justified by models of full-information rational expectations, in conjunction with linear econometric specifications, such as vector autoregressions (VARs) and local projections (LPs, Jordà, 2005). However, as carefully documented in Coibion (2012) and in Ramey (2016), the lack of robustness of the responses to monetary policy shocks ranges through both identification schemes, and empirical specifications.

Moving from these considerations, we reassess the empirical evidence on the effects of monetary policy shocks by adopting an identification strategy that is robust to the presence of informational frictions, in conjunction with a novel econometric method that is robust to model misspecifications of different nature. Our strategy is in two steps. First, we design an instrument for monetary policy shocks that accounts for

\footnotetext{
${ }^{1}$ Amongst many others, Friedman and Meiselman (1963), Sims (1972, 1980), Bernanke and Blinder (1992), Leeper et al. (1996), Christiano et al. (1999), Romer and Romer (2004), Uhlig (2005), Gertler and Karadi (2015). Comprehensive literature reviews are in Christiano et al. (1999) and in Ramey (2016).
} 
the monetary authority and private agents potentially having non-nested information sets, and hence entertaining different beliefs about the economy. ${ }^{2}$ Second, we introduce Bayesian Local Projections (BLP) as a flexible and robust method that spans the space between VARs and LPs and, in doing so, it imposes minimum restrictions on the shape of the estimated impulse response functions (IRFs). We show that most of the lack of stability reported in previous studies can be explained by the compounded effects of the unrealistic assumptions of full information that are often made when identifying the shocks, and the use of severely misspecified models for the estimation of the dynamic responses. We then set to study how monetary policy shocks transmit to the economy, how they affect financial conditions, and how do agents' expectations react to them. We document that responses obtained with our proposed methodology are consistent with standard macroeconomic theory, are stable over time, and seldom display puzzles. ${ }^{3}$

Identification. As observed in Blinder et al. (2008), imperfect and asymmetric information between the public and the central bank are the norm, not the exception, in monetary policy. However, while this observation has informed many theoretical attempts to include informational imperfections in the modelling of monetary policy, it has been largely disregarded in the empirical identification of the shocks. ${ }^{4}$ Indeed, popular instruments for monetary policy shocks that are constructed in leading identification schemes can be thought of as assuming that either the central bank (e.g. Romer and Romer, 2004) or market participants (e.g. Gertler and Karadi, 2015) enjoy perfect information. Under these assumptions, controlling for the information set of the perfectly informed agent is sufficient to identify the shock. If all agents in the economy enjoyed full information, different instruments would deliver identical results. On the contrary,

\footnotetext{
${ }^{2}$ Our methodology builds on the insights provided by models of imperfect - noisy and sticky information and asymmetric information (e.g. Woodford, 2001; Mankiw and Reis, 2002; Sims, 2003; Mackowiak and Wiederholt, 2009) and, empirically, combines insights from Romer and Romer (2004)'s narrative identification identification and the high-frequency identification (HFI) of Gertler and Karadi (2015).

${ }^{3}$ While not ruling out the possibility of time-variation in the transmission coefficients of monetary policy (see Primiceri, 2005), our results show that the effects of monetary policy are more stable than was previously reported. Our results are robust to a variety of severe tests, amongst others on the sample used, the chosen lag length, the composition of the vector of endogenous variables considered, and the BLP prior specification.

${ }^{4}$ Reviews on models of imperfect information and learning in monetary policy are in Mankiw and Reis (2010), Sims (2010), and Gaspar, Smets and Vestin (2010).
} 
responses may instead diverge with dispersed information.

This paper reviews and expands the evidence on the presence of informational frictions that are relevant for monetary policy. We formally test and reject the null of full information for all the instruments for monetary policy shocks used in leading identification schemes. First, high-frequency instruments are predictable (see also MirandaAgrippino, 2016) and autocorrelated (see also Ramey, 2016). We interpret this as an indication of the sluggish adjustment of expectations, in line with what documented for different types of economic agents using survey data. This is the emerging feature of models of imperfect information. ${ }^{5}$ Second, market-based revisions of expectations that follow policy announcements correlate with central banks' private macroeconomic forecasts (see also Barakchian and Crowe, 2013; Gertler and Karadi, 2015; Ramey, 2016; Miranda-Agrippino, 2016). We think of this as evidence of the 'signalling channel' discussed in Melosi (2017) - i.e. the transfer of central banks' private information implicitly disclosed through policy actions, and due to the information asymmetry between private agents and the central bank (Romer and Romer, 2000). Finally, we show that narrative surprises, obtained with respect to the central bank's information set only (Romer and Romer, 2004; Cloyne and Hürtgen, 2016), are equally affected by informational frictions. Specifically, they are autocorrelated, predictable by past information, and may contain anticipated policy shifts - e.g. forwards guidance announcements.

Taking stock of this evidence, we define monetary policy shocks as exogenous shifts in the policy instrument that surprise market participants, are unforecastable, and are not due to the central bank's systematic response to its own assessment of the macroeconomic outlook. Hence, we construct an instrument for monetary policy shocks by projecting market-based monetary surprises on their own lags, and on the central bank's information set, as summarised by Greenbook forecasts. ${ }^{6}$ We use this informationally-

\footnotetext{
${ }^{5}$ See, for example, Mankiw et al. (2004), Coibion and Gorodnichenko (2012), Coibion and Gorodnichenko (2015), and Andrade and Le Bihan (2013).

${ }^{6}$ Market-based monetary surprises are the high-frequency price revisions in traded interest rates futures that are triggered by a policy announcement. In using financial markets instruments to measure the unexpected component of monetary policy we connect to a large literature pioneered by Rudebusch (1998) and Kuttner (2001) and whose notable contributions include, among others, Bernanke and Kuttner (2005); Gürkaynak (2005); Gürkaynak, Sack and Swanson (2005); Campbell, Fisher, Justiniano and Melosi (2016); Caldara and Herbst (2016); Gilchrist, López-Salido and Zakrajšek (2015). Barak-
} 
robust instrument to identify the shocks from the stochastic component of an autoregressive model (Stock and Watson, 2012; Mertens and Ravn, 2013).

Transmission. From a classical point of view, choosing between iterated (VAR) and direct (LP) impulse responses involves a trade-off between bias and estimation variance: the iterated method produces more efficient parameters estimates than the direct one, but it is more prone to bias if the model is misspecified. Because it is implausible that generally low-order autoregressive models are correctly specified, the robustness of LP to model misspecification makes them a theoretically preferable procedure. Common misspecifications can in fact easily arise in relation to the chosen lag order, insufficient information set considered, unmodelled moving average components, and non-linearities (Braun and Mittnik, 1993; Schorfheide, 2005). Yet, empirical studies indicate that due to high estimation uncertainty, and over parametrisation, the theoretical gains from direct methods are rarely realised in practice (see Marcellino, Stock and Watson, 2006; Kilian and Kim, 2011).

We think of this as a standard trade-off in Bayesian estimation, and design Bayesian Local Projection (BLP) to effectively bridge between the two specifications. ${ }^{7}$ BLP responses are estimated using conjugate priors centred around an iterated VAR estimated on a pre-sample. Intuitively, the prior gives weight to the belief that economic time series processes can be described in first approximation by linear models such as VARs. Extending the argument in Giannone, Lenza and Primiceri (2015), we treat the overall informativeness of the priors as an additional model parameter for which we specify a prior distribution, and choose it as the maximiser of the posterior likelihood. As a result, the posterior mean of BLP IRFs is an optimally weighted combination of VAR and LP-based IRFs. We find that the data tend to deviate from the VAR prior the farther away the horizon, resulting in an optimal level of prior shrinkage that is a monotonic

chian and Crowe (2013) and Miranda-Agrippino (2016) have proposed identifications based on monetary surprises that control for the central bank's internal forecasts. Differently from these papers, our methodology incorporates intuition stemming from models of imperfect information.

${ }^{7}$ Our approach has an alternative classical interpretation provided by the theory of 'regularisation' of statistical regressions (see, for example, Chiuso, 2015). Another approach to LP regularisation has been proposed more recently in Barnichon and Brownlees (2016). A different Bayesian approach to inference on structural IRFs has been proposed by Plagborg-Moller (2015). Barnichon and Matthes (2014) have propounded a method to estimate IRFs using Gaussian basis functions. 
non-decreasing function of the forecast horizon, or projection lag.

Empirical Findings. Using our methodology, we study the transmission of monetary policy shocks on a large and heterogenous set of both macroeconomic and financial variables, as well as on private sector expectations, and medium and long-term interest rates. We find that a monetary contraction is unequivocally and significantly recessionary. Output and prices contract and there is no evidence of puzzles. We document evidence compatible with many of the standard channels of monetary transmission (Mishkin, 1996). We analyse in detail the response of interest rates at short, medium, and very long maturities and find important but very short-lived effects of policy on the yield curve (Romer and Romer, 2000; Ellingsen and Soderstrom, 2001). Also, we find evidence of a powerful credit channel that magnifies the size of the economic contraction through the responses of both credit and financial markets (Bernanke and Gertler, 1995; Gertler and Karadi, 2015; Caldara and Herbst, 2016). Moreover, we document a deterioration of the external position sustained by a significant appreciation of the domestic currency. The expectational channel is also activated: agents revise their macroeconomic forecasts in line with the deteriorating fundamentals. Finally, we document that BLP responses optimally deviate from the VAR responses as the horizon grows. As a result of this, BLP IRFs revert to trend much faster than VAR IRFs do. This has potentially important implications for the policy debate, and particularly in relation to the length of the policy horizons, the duration of which is typically calibrated on VAR evidence.

\section{Identification}

In the presence of informational frictions, monetary policy shock are best thought of as shifts to the policy rate that are both unforeseen by market participants, and not due to the central bank's concerns about either current or anticipated changes in the economic conditions. Building on the high-frequency identification of Gertler and Karadi (2015) and Romer and Romer (2004)'s narrative approach, we propose a novel instrument for monetary policy shocks that takes into account both the slow absorption of information 
in the economy, and the signalling channel of monetary policy that arises from the asymmetry of information between the central bank and market participants.

We provide a microfoundation for our identification strategy using a simple model of noisy information, where both private agents and the central bank update their information sets and make decisions based on noisy signals about the state of the economy. Using the the model's predictions, we then test for the presence of informational frictions in our and other leading instruments for monetary policy shocks.

\subsection{An Informationally-robust Instrument}

We construct our instrument for monetary policy shocks as the component of market surprises triggered by policy announcements that is orthogonal to both central bank's economic projections, and to past market surprises. Operationally, we proceed in three steps. First, following Gertler and Karadi (2015), we build monthly market surprises as the sum of the daily series in Gürkaynak, Sack and Swanson (2005). ${ }^{8}$ We think of these price revisions in interest rates futures as proxies for expectation revisions triggered by FOMC announcements. Second, we regress these monthly surprises onto $(i)$ their lags, to control for the autocorrelation due to the slow absorption of information - the trademark of imperfect information -, and (ii) onto Greenbook forecasts and forecast revisions for real output growth, inflation and the unemployment rate, as in Romer and Romer (2004), to control for the central bank's private information, and hence for the signalling channel of monetary policy.

Specifically, we recover an instrument for monetary policy shocks using the residuals of the following regression:

$$
\begin{aligned}
m p s_{t}= & \alpha_{0}+\sum_{i=1}^{p} \alpha_{i} m p s_{t-i}+ \\
& +\sum_{j=-1}^{3} \theta_{j} F_{t}^{c b} x_{q+j}+\sum_{j=-1}^{2} \vartheta_{j}\left[F_{t}^{c b} x_{q+j}-F_{t-1}^{c b} x_{q+j}\right]+z_{t} .
\end{aligned}
$$

\footnotetext{
${ }^{8}$ Differently from Gertler and Karadi (2015), however, we use an unweighted monthly aggregate of daily surprises.
} 
$m p s_{t}$ denotes the market-based monetary surprise that follows the FOMC announcements in month $t . F_{t}^{c b} x_{q+j}$ denotes Greenbook forecasts for quarter $q+j$ made at time $t$, where $q$ denotes the current quarter. $\left[F_{t}^{c b} x_{q+j}-F_{t-1}^{c b} x_{q+j}\right]$ is the revised forecast for $x_{q+j}$ between two consecutive meetings. For each surprise, the latest available forecast is used. $x_{q}$ includes output, inflation, and unemployment. ${ }^{9}$

The daily series used to construct the monthly monetary policy surprises $\left(m p s_{t}\right)$ are the intraday movements in the fourth federal funds futures contracts $\left(F F 4_{t}\right)$ that are registered within a 30-minute window surrounding the time of the FOMC announcements. These contracts have an average maturity of about three months and settle based on the average effective federal funds rate prevailing on the expiry month. Their price can therefore be thought of as embedding markets' forecasts about future policy rates. Under the assumption of a constant risk premium, a price revision that follows a monetary policy announcement is a measure of the component of policy that is unexpected by market participants, given their pre-announcement information se (see e.g. Gürkaynak et al., 2005).

In Figure 1 we plot the original monetary surprise $m p s_{t}\left(F F 4_{t}\right.$, orange line) and our instrument for the monetary policy shock $z_{t}\left(M P I_{t}\right.$, blue line). Interestingly, the chart shows that significant discrepancies arise during times of economic distress (see also Figure C.1 in Appendix C). More importantly, however, the difference between these two series resides in their informational content. Indeed, as results in Section 1.3 show, the $M P I_{t}$ series is the only one that survives the tests for informational frictions.

\subsection{A Simple Noisy Information Model}

As observed in Coibion and Gorodnichenko (2015), a common prediction of models of imperfect information is that average expectations respond more gradually to shocks to fundamentals than do the variables being forecasted. This implies that revisions of expectations - and importantly movements in market prices - can be correlated over time, and contain information on both current and past structural shocks. Moreover,

\footnotetext{
${ }^{9}$ Following Romer and Romer (2004) we only include the nowcast for the level of the unemployment rate to mitigate the effects of the high correlation between output and unemployment.
} 


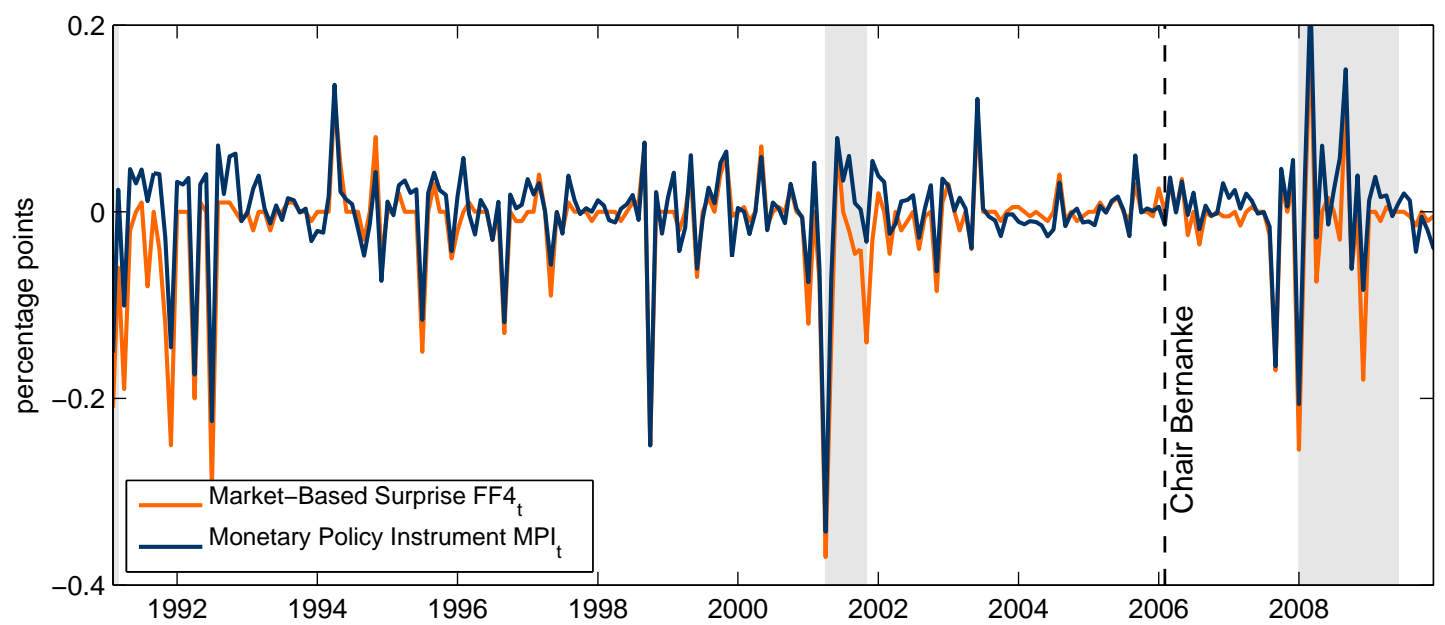

Note: market-based surprises conditional on private agents' information set $F F 4_{t}$ (orange line), residual to Eq. (1) $M P I_{t}$ (blue, solid). Shaded areas denote NBER recessions.

due to the asymmetry of information between policy makers and market participants, observable policy actions convey information about fundamentals. In this section we introduce a simple model of noisy and asymmetric information that can account for all these features. Derivations of the main formulas are in Appendix A.

Let us consider an economy whose $k$-dimensional vector of macroeconomic fundamentals evolves following an autoregressive process

$$
x_{t}=\rho x_{t-1}+\xi_{t} \quad \xi_{t} \sim \mathcal{N}\left(0, \Sigma_{\xi}\right) .
$$

$\xi_{t}$ is the vector of structural shocks. Any period $t$ is divided into two stages. An opening stage $\underline{t}$, and a closing stage $\bar{t}$. At $\underline{t}$, shocks are realised. Agents and central banks do not observe $x_{t}$ directly, rather, they use a Kalman filter to form expectations about $x_{t}$ based on the private noisy signals that they receive. We use $s_{i, \underline{t}}$ and $s_{c b, \underline{t}}$ to denote the signals received at time $\underline{t}$ by private agents and the central bank respectively. Similarly, we use $F_{i, \underline{t}}$ and $F_{c b, \underline{t}}$ to denote their respective conditional forecasts. The information flow is sketched in Figure 2. 


\section{Figure 2: The Information Flow}

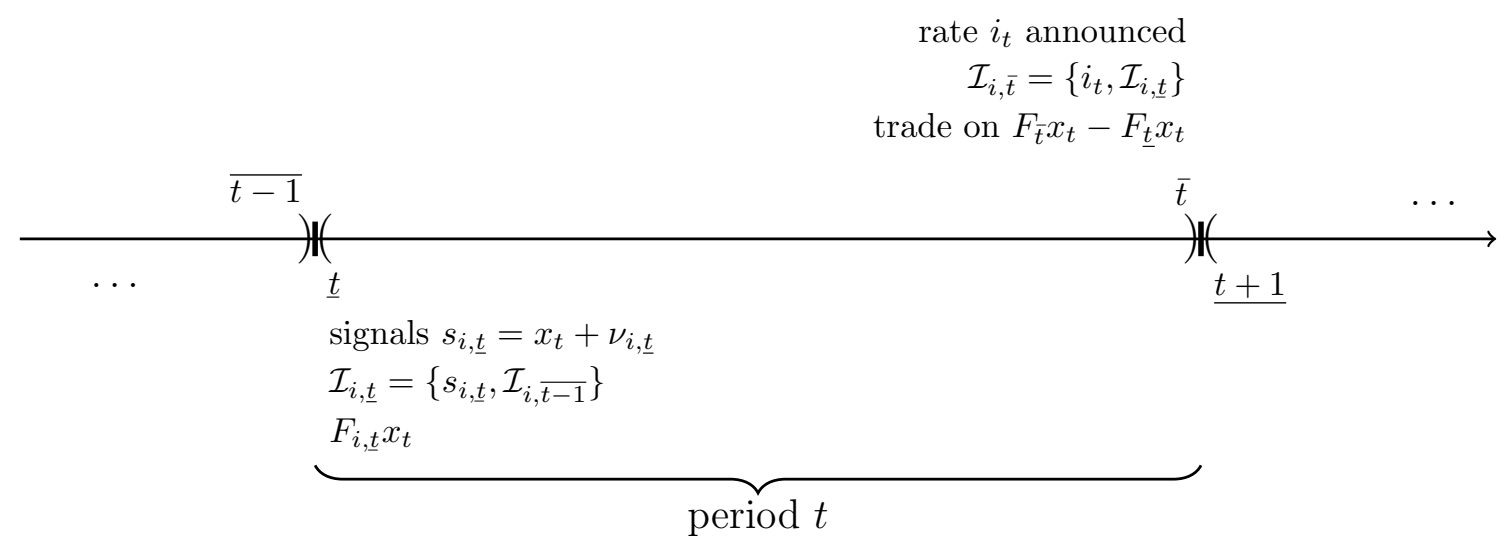

Note: Each period $t$ has a beginning $\underline{t}$ and an end $\bar{t}$. At $\underline{t}$ agents (both private and central bank) receive noisy signals $s_{i, \underline{t}}$ about the economy $x_{t}$, and update their forecasts $F_{i, \underline{t}} x_{t}$ based on their information set $\mathcal{I}_{i, \underline{t}}$. At $\bar{t}$ the central bank announces the policy rate $i_{t}$ based on its forecast $F_{c b, \underline{t}} x_{t}$. Agents observe $i_{t}$, infer $F_{c b, t} x_{t}$, and form $F_{i, \bar{t}} x_{t}$. Trade is a function of the aggregate expectation revision between $\underline{t}$ and $\bar{t}$.

Agents can trade securities (e.g. futures contracts) based on $i_{t+h}$, the realisation of the policy rate at time $t+h$. The price of a futures contract on $i_{t+h}$ reflects their aggregate expectation about $x_{t}$, as follows

$$
p_{\underline{t}}\left(i_{t+h}\right)=F_{\underline{t}} x_{t+h}+\mu_{t},
$$

where $\mu_{t}$ is a stochastic component, such as the risk premium in Gürkaynak et al. (2005), or a stochastic process related to the supply of assets (see Hellwig, 1980; Admati, 1985).

At $\bar{t}$, and conditional on its own forecast $F_{c b, \underline{t}} x_{t}$, the central bank sets the interest rate for the current period using a Taylor rule

$$
i_{t}=\phi_{0}+\phi_{x}^{\prime} F_{c b, \underline{t}} x_{t}+u_{t}
$$

where $u_{t}$ denotes the monetary policy shock and $K_{c b}$ is the central bank's Kalman gain. ${ }^{10}$ Having observed the current policy rate, agents update their forecasts, and

\footnotetext{
${ }^{10}$ Interestingly, the interest rate smoothing in the monetary policy rule arises naturally from the
} 
trade at $\bar{t}$. Conditional on $i_{t-1}$, observing the interest rate is equivalent to receiving a public signal with common noise $\tilde{s}_{c b, \bar{t}}$ from the central bank. Because of this forecast update triggered by the policy announcement, the price of futures contracts is revised by an amount proportional to the average (in population) revision of expectations, that is

$$
p_{\bar{t}}\left(i_{t+1}\right)-p_{\underline{t}}\left(i_{t+1}\right) \propto\left(F_{\bar{t}} x_{t+1}-F_{\underline{t}} x_{t+1}\right)
$$

where $F_{\underline{t}} x_{t+1}$ and $F_{\bar{t}} x_{t+1}$ are the average forecast updates that follow $s_{i, \underline{t}}$ and $\tilde{s}_{c b, \bar{t}}$. In Appendix A we provide a proof of the following lemma.

Lemma. Following a central bank policy announcement, aggregate expectations revisions evolve as

$$
\begin{aligned}
F_{\bar{t}} x_{t}-F_{\underline{t}} x_{t}= & \left(1-K_{2}\right)\left(1-K_{1}\right)\left[F_{\overline{t-1}} x_{t}-F_{\underline{t-1}} x_{t}\right] \\
& +K_{2}\left(1-K_{1}\right) \xi_{t}+K_{2}\left[\nu_{c b, \underline{t}}-\left(1-K_{1}\right) \rho \nu_{c b, \underline{t-1}}\right] \\
& +K_{2}\left(K_{c b} \phi_{x}^{\prime}\right)^{-1}\left[u_{t}-\rho\left(K_{1}-K_{c b}\right) u_{t-1}+\left(1-K_{1}\right)\left(1-K_{c b}\right) \rho^{2} u_{t-2}\right],
\end{aligned}
$$

where $K_{1}$ and $K_{2}$ denote the agents' Kalman gains employed in $F_{i, \underline{t}}$ and $F_{i, \bar{t}}$ respectively, $K_{c b}$ is the central bank's Kalman gain, $u_{t}$ is a monetary policy shock, and $\nu_{c b}$ is the central bank's observational noise.

Two emerging features of models of imperfect information that have important implications for the identification of monetary policy shocks are in evidence in Eq. (7). First, average expectation revisions (and thus high-frequency surprises) - a direct measure of the shocks under full information -, are orthogonal neither to their past, nor to past available information due to the slow absorption of new information over time. Second, observable policy actions can transfer information about economic fundamentals from the policy maker to market participants. Indeed, the second term in Eq. (7) signal extraction problem faced by the central bank. Indeed, it is possible to rewrite Eq. (4) as

$$
i_{t}=\left[1-\left(1-K_{c b}\right) \rho\right] \phi_{0}+\left(1-K_{c b}\right) \rho i_{t-1}+K_{c b} \phi_{x}^{\prime} s_{c b, \underline{t}}-\left(1-K_{c b}\right) \rho u_{t-1}+u_{t} .
$$

The policy rate at any time $t$ is a function of current and past signals, and of current and past monetary policy shocks. 
that depends on the structural shocks $\xi_{t}$ is the update of expectations due to the revisions of beliefs about the state of the economy that follow the policy announcement - i.e. the 'the signalling channel' (see Melosi, 2017; Hubert and Maule, 2016). This implicit disclosure of information can strongly influence the transmission of monetary impulses, and the central bank's ability to stabilise the economy. Empirically, if not accounted for, it can lead to both price and output puzzles. In fact, a policy rate hike can be interpreted by informationally constrained agents either as a deviation of the central bank from its monetary policy rule - i.e. a contractionary monetary shock -, or as an endogenous response to inflationary pressures expected to hit the economy in the near future. Despite both resulting in a visible rate increase, these two scenarios imply profoundly different evolutions for macroeconomic aggregates, and agents' expectations (see e.g. Campbell et al., 2012, and Section 5). ${ }^{11}$

Eq. (7) provides us with testable predictions about market-based monetary surprises: in the presence of imperfect information they are $(i)$ serially correlated, $(i i)$ predictable using other macroeconomic variables, and (iii) correlated with the central bank's projections of relevant macroeconomic variables. We empirically document the testable implications of these three predictions in the reminder of this section.

\subsection{Testing for Imperfect Information}

Tables 1 and 2 report the tests for $(i)$ serial correlation, (ii) correlation with the Fed's internal forecasts, and (iii) predictability with lagged state variables, for our and other commonly used instruments for monetary policy shocks. These are the monthly market surprises extracted form the fourth federal funds futures $\left(F F 4_{t}\right)$, and constructed as the sum of daily series in Gürkaynak et al. (2005); the average monthly market surprise in Gertler and Karadi (2015), FF4t $4_{t}^{G K}$; and the Romer and Romer (2004)'s narrative shock series, $M P N_{t} \cdot{ }^{12}$ All regressions displayed are estimated at monthly frequency on

\footnotetext{
${ }^{11}$ It is also worth noticing that the third term in Eq. (7) is the aggregate noise contained in the policy announcement, due to the central bank's noisy observation of the state of the economy. This too can be thought of as another exogenous policy shift (see Orphanides, 2003).

${ }^{12}$ We use an extension of this series up to the end of 2007 constructed in Miranda-Agrippino and Rey (2015).
} 
Table 1: Serial Correlation and Central Bank Signalling

\begin{tabular}{|c|c|c|c|c|c|c|c|c|c|}
\hline & & $F F 4_{t}$ & & & $F F 4_{t}^{G K}$ & & $M P N$ & & \\
\hline$A R(4)$ & $\begin{array}{l}2.219 \\
{[0.068]^{*}}\end{array}$ & & & $\begin{array}{l}10.480 \\
{[0.000]^{* * *}}\end{array}$ & & & $\begin{array}{l}16.989 \\
{[0.000]^{* * *}}\end{array}$ & & \\
\hline $\begin{array}{l}\text { Greenbook } \\
\text { Forecast }\end{array}$ & & $\begin{array}{l}2.287 \\
{[0.011]^{* *}}\end{array}$ & & & $\begin{array}{l}3.377 \\
{[0.000]^{* * *}}\end{array}$ & & & - & \\
\hline $\begin{array}{l}\text { Greenbook } \\
\text { Revision }\end{array}$ & & & $\begin{array}{l}2.702 \\
{[0.007]^{* * *}}\end{array}$ & & & $\begin{array}{l}3.719 \\
{[0.000]^{* * *}}\end{array}$ & & & - \\
\hline$R^{2}$ & 0.021 & 0.080 & 0.068 & 0.142 & 0.129 & 0.100 & 0.237 & - & - \\
\hline$N$ & 230 & 238 & 238 & 230 & 238 & 238 & 207 & - & - \\
\hline
\end{tabular}

Note: Regressions on Greenbook forecasts and forecast revisions include a constant and 1 lag of the dependent variable. From left to right, the monthly surprise in the fourth federal funds future $\left(F F 4_{t}\right)$, the instrument in Gertler and Karadi $(2015)\left(F F 4_{t}^{G K}\right)$, the narrative series of Romer and Romer (2004) $\left(M P N_{t}\right)$. 1990:2009. t-statistics are reported in square brackets, ${ }^{*} p<0.1,{ }^{* *} p<0.05,{ }^{* * *} p<0.01$, robust SE.

all available observations over the sample 1990:01 - 2009:12. ${ }^{13}$

Table 1 reports $F$ statistics and relative significance levels for the projection of monetary surprises onto own lags and central bank's forecast and revisions to forecasts for output, inflation and unemployment. The narrative instrument is orthogonal to these variables by construction. The $M P I_{t}$ instrument is orthogonal to both sets of variables by construction. The null is strongly rejected for both the Greenbook forecasts themselves and their revision, and for both types of monthly market surprises. ${ }^{14}$ We note, however, that the bulk of predictability resides in the forecast revisions between consecutive meetings. This is consistent with the characteristics of the signalling channel. In the first row of the table, we note that all three series are autocorrelated. Extending the number of lags to 12 does not alter the evidence. Also, we note that while the weighting scheme adopted in Gertler and Karadi (2015) enhances the autocorrelation in the average monthly surprises, the null of no time dependence is rejected also for the

\footnotetext{
${ }^{13}$ We exclude the September 2001 observation from regressions involving financial markets surprises to address the concerns in Campbell et al. (2012). Also, for these series we note that results are not driven by the observations dating earlier than 1994 (see Appendix C).

${ }^{14}$ Related results are in Barakchian and Crowe (2013), Gertler and Karadi (2015), Ramey (2016) and Miranda-Agrippino (2016).
} 
Table 2: Predictability of Monetary Policy Instruments

\begin{tabular}{|c|c|c|c|c|c|c|c|c|}
\hline \multirow[b]{2}{*}{$f_{1, t-1}$} & \multicolumn{2}{|c|}{$F F 4_{t}$} & \multicolumn{2}{|c|}{$F F 4_{t}^{G K}$} & \multicolumn{2}{|c|}{$M P N_{t}$} & \multicolumn{2}{|c|}{$M P I_{t}$} \\
\hline & -0.012 & {$[-1.97]^{*}$} & -0.011 & {$[-2.74]^{* * *}$} & -0.103 & {$[-4.13]^{* * *}$} & 0.006 & {$[0.98]$} \\
\hline$f_{2, t-1}$ & 0.001 & {$[0.38]$} & 0.004 & {$[1.79]^{*}$} & -0.005 & {$[-0.45]$} & 0.005 & {$[1.56]$} \\
\hline$f_{3, t-1}$ & 0.002 & {$[0.41]$} & -0.001 & {$[-0.23]$} & -0.035 & {$[-2.21]^{* *}$} & 0.001 & {$[0.29]$} \\
\hline$f_{4, t-1}$ & 0.015 & {$[2.09]^{* *}$} & 0.008 & {$[1.92]^{*}$} & 0.068 & {$[2.71]^{* * *}$} & 0.005 & {$[0.70]$} \\
\hline$f_{5, t-1}$ & 0.002 & {$[0.26]$} & 0.001 & {$[0.12]$} & 0.017 & {$[0.61]$} & 0.008 & [1.18] \\
\hline$f_{6, t-1}$ & -0.011 & {$[-2.19]^{* *}$} & -0.007 & {$[-2.58]^{* *}$} & 0.008 & {$[0.57]$} & -0.008 & {$[-1.63]$} \\
\hline$f_{7, t-1}$ & -0.010 & {$[-1.69]^{*}$} & -0.006 & {$[-1.40]$} & -0.053 & {$[-2.85]^{* * *}$} & -0.004 & {$[-0.54]$} \\
\hline$f_{8, t-1}$ & -0.001 & {$[-0.35]$} & 0.001 & {$[0.32]$} & -0.042 & {$[-2.38]^{* *}$} & -0.001 & {$[-0.15]$} \\
\hline$f_{9, t-1}$ & -0.002 & {$[-0.59]$} & -0.002 & {$[-0.53]$} & -0.037 & {$[-1.65]$} & 0.000 & {$[0.07]$} \\
\hline$f_{10, t-1}$ & 0.004 & {$[0.75]$} & 0.000 & {$[-0.03]$} & -0.030 & {$[-2.54]^{* *}$} & -0.003 & {$[-0.70]$} \\
\hline$R^{2}$ & 0.073 & & 0.140 & & 0.202 & & 0.033 & \\
\hline$F$ & 2.230 & & 3.572 & & 3.372 & & 2.225 & \\
\hline$p$ & 0.014 & & 0.000 & & 0.000 & & 0.014 & \\
\hline$N$ & 236 & & 236 & & 213 & & 224 & \\
\hline
\end{tabular}

Note: Regressions include a constant and 1 lag of the dependent variable. 1990:2009. From left to right, the monthly surprise in the fourth federal funds future $\left(F F 4_{t}\right)$, the instrument in Gertler and Karadi (2015) $\left(F F 4_{t}^{G K}\right)$, the narrative series of Romer and Romer (2004) $\left(M P N_{t}\right)$, and the informationally robust instrument constructed in Section $1.1\left(M P I_{t}\right)$. The ten dynamic factors are extracted from the set of monthly variables in McCracken and $\mathrm{Ng}$ (2015). t-statistics are reported in square brackets, * $p<0.1,{ }^{* *} p<0.05,{ }^{* * *} p<0.01$, robust standard errors.

unweighted monthly surprises. ${ }^{15}$

In Table 2 we project the different measures of monetary policy shocks (including our own) on a set of lagged macro-financial factors extracted from the collection of monthly variables assembled in McCracken and $\mathrm{Ng}$ (2015). The dataset that we use for the factors extraction counts over 130 monthly series that cover all the main macroeconomic aggregates, and a number of financial indicators. The factors enter the regressions with a month's lag. Results in Table 2 confirm the predictability of market-based monetary surprises using past information. ${ }^{16}$ They also show that narrative accounts of 'unanticipated' interest rate changes are similarly predictable by state variables which

\footnotetext{
${ }^{15}$ As pointed out in Coibion and Gorodnichenko (2012), the OLS coefficients in the autoregression can be biased as a consequence of the presence of noisy signals. The bias in our case is likely to be negative, as shown in the Appendix (Eq. A.18).

${ }^{16}$ Miranda-Agrippino (2016) shows that market-based monetary surprises are significantly predictable by lagged factors intended to summarise the pre-existing economic and financial conditions in the economy. The predictability holds across both financial instruments and countries.
} 
are a function of past structural shocks. ${ }^{17}$

Our results on the predictability of the narrative series are novel, and can be rationalised as follows. The construction of $M P N_{t}$ amounts to running a regression motivated by an empirical Taylor rule, and using the residuals as a measure of the shocks $u_{t}$. If, however, the deviation from the rule is autocorrelated, the residuals of the projection of the policy rate onto central bank's forecasts are not the structural shock $u_{t}$ - agents can try to forecast it using past information. Moreover, the projection residuals may also be contaminated by announced policy changes, as is the case e.g. for forward guidance. ${ }^{18}$

\section{Transmission}

Correct inference of the dynamic effects of monetary policy shocks hinges on the interaction between the identification strategy and the modelling choice. Modern macroeconomics thinks of the residuals of autoregressive models as structural stochastic innovations - i.e. combinations of economically meaningful shocks -, and identifies the ones of interest using a variety of different schemes. Once the structural shocks are identified, the autoregressive coefficients of the model are employed to study the transmission of the exogenous disturbances over time. While considerable attention has been devoted to the identification of the shocks, the issues related to model specification have often been overlooked (see also discussion in Caldara and Herbst, 2016).

The standard approach in empirical monetary economics is to employ small VARs consisting of a policy indicator and a few macroeconomic variables of interest. However, it is well understood that such small VARs are likely to be misspecified. ${ }^{19}$ In this case,

\footnotetext{
${ }^{17}$ Factors are estimated using last vintage data which are likely to incorporate revisions to early releases. While this may not be information readily available to agents, it is worth to observe that in a perfect information world markets aggregate information efficiently, and there is no role for data revisions and national accounting offices.

${ }^{18}$ Also, if the central bank sets the policy rate conditioning on other indicators such as financial and fiscal variables (see e.g. Croushore and van Norden, 2017), the projection residuals will also be endogenous to these variables. This again may show up as predictability with factors.

${ }^{19}$ Misspecifications can arise along several dimensions. First, the information set incorporated in a small-size VAR can fail to capture all of the dynamic interactions that are relevant to the propagation of the shock of interest. Second, the lag order of the underlying process may potentially be underestimated. Also, if the disturbances of the underlying data generating process are a moving average process, fitting a low-order, or indeed any finite-order VAR may be inadequate. Finally, several possible non-linearities
} 
estimates of the parameters - transmission coefficients and covariance matrix alike - are inconsistent (Braun and Mittnik, 1993). In turn, this affects both the identification of the disturbances and the estimated impulse responses. These concerns have motivated the adoption of more flexible, 'non-parametric' empirical specifications, such as Jordà (2005)'s local projections (LP).

From a classical perspective, choosing between iterated VARs and direct methods such as LP involves a sharp trade-off between bias and estimation variance: the iterated method produces more efficient parameters estimates than the direct method, but it is more prone to bias if the one-step-ahead model is misspecified. ${ }^{20}$ We think of this as a standard trade-off in Bayesian estimation and propose a Bayesian approach to Local Projection (BLP) that optimally spans the model space between VAR-based and LP-based impulse responses (IRFs). Intuitively, BLP regularises LP responses using priors centred around an iterated VAR, while allowing the data structure to select the optimal degree of departure form the priors at each horizon. This approach has a dual interpretation in classic regularisation techniques.

\subsection{Bayesian Local Projections}

VARs recover impulse responses by iterating up to the relevant horizon the coefficients of a system of one-step ahead reduced-form equations

$$
y_{t+1}=B y_{t}+\varepsilon_{t+1} \quad \varepsilon_{t} \sim \mathcal{N}\left(0, \Sigma_{\varepsilon}\right),
$$

where $y_{t}=\left(y_{t}^{1}, \ldots, y_{t}^{n}\right)^{\prime}$ is a $(n \times 1)$ random vector of macroeconomic variables, $B$ is an $n$-dimensional matrix of coefficients, and $\varepsilon_{t}$ is an $(n \times 1)$ vector of reduced-form

of different nature may be empirically significant - such as time-variation or state-dependency of some of the parameters, and non-negligible higher order terms.

${ }^{20}$ In the forecasting literature, the distinction between direct LP IRFs and iterated VAR IRFs corresponds to the difference between direct and iterated forecasts (see Marcellino, Stock and Watson, 2006; Pesaran, Pick and Timmermann, 2011; Chevillon, 2007, amongst others). Direct forecasts tend to have higher sample MSFEs than iterated forecasts, and become increasingly less desirable as the forecast horizon lengthens (see Marcellino et al., 2006). Also, LP asymptotic intervals are often less accurate than the bias-adjusted VAR bootstrapped intervals, notwithstanding their large average width (see Kilian and Kim, 2011). 
innovations. ${ }^{21}$ Conversely, LPs estimate the IRFs directly from a set of linear regressions of the form

$$
y_{t+h}=B^{(h)} y_{t}+\varepsilon_{t+h}^{(h)}, \quad \varepsilon_{t+h}^{(h)} \sim \mathcal{N}\left(0, \Sigma_{\varepsilon}^{(h)}\right) \quad \forall h=1, \ldots, H
$$

Being a combination of one-step-ahead forecast errors, the projection residuals $\varepsilon_{t+h}^{(h)}$ are serially correlated and heteroskedastic.

The horizon- $h$ impulse response functions from the two methods are given by

$$
\begin{aligned}
& \operatorname{IRF}_{h}^{\mathrm{VAR}}=B^{h} A_{0}^{-1}, \\
& \mathrm{IRF}_{h}^{\mathrm{LP}}=B^{(h)} A_{0}^{-1},
\end{aligned}
$$

where $A_{0}$ identifies the mapping between the structural shocks $u_{t}$ and the reduced-form one-step-ahead forecast errors, i.e. $\varepsilon_{t}=A_{0}^{-1} u_{t}$. Assuming the VAR to be the true description of the data generating process, the coefficients and residuals of an iterated VAR can be readily mapped into those of LP, yielding

$$
\begin{aligned}
& B^{(h)} \longleftrightarrow B^{(\mathrm{VAR}, h)}=B^{h}, \\
& \varepsilon_{t+h}^{(h)} \longleftrightarrow \varepsilon_{t+h}^{(\mathrm{VAR}, h)}=\sum_{j=1}^{h} B^{h-j} \varepsilon_{t+h} .
\end{aligned}
$$

Three observations are in order. First, conditional on the underlying data generating process being the linear model in Eq. (8), and abstracting from estimation uncertainty, the IRFs computed with the two methods should coincide. Second, as shown by Eq. (13), conditional on the linear model being correctly specified, LPs are bound to have higher estimation variance due to (strongly) autocorrelated residuals. ${ }^{22}$ Third, given that for $h=1$ VARs and LPs coincide, the identification problem is identical for the two methods. In other words, given an external instrument or a set of theory-based

\footnotetext{
${ }^{21}$ To provide the gist of our apporach and simplify the notation, we omit deterministic components from Eq. (8), and consider a simple $\operatorname{VAR}(1)$ case or, equivalently, a $\operatorname{VAR}(\mathrm{p})$ in companion form. A detailed description of the method is reported in Appendix B.

${ }^{22}$ Most macroeconomic variables are close to $\mathrm{I}(1)$ and even $\mathrm{I}(2)$ processes. Hence LP residuals are likely to be strongly autocorrelated.
} 
assumptions, the way in which the $A_{0}$ matrix is derived from either VARs or LPs coincides.

The map in Eq. (12-13) provides a natural bridge between the two empirical specifications, which we exploit to inform the priors for our method. ${ }^{23}$ For the coefficients of Eq. (9) at each horizon $h$, and leaving temporarily aside concerns about the structure of the projection residuals, we specify standard conjugate Normal-inverse Wishart informative priors of the form

$$
\begin{aligned}
& \Sigma_{\varepsilon}^{(h)} \mid \lambda^{(h)} \sim \mathcal{I} \mathcal{W}\left(\Psi_{0}^{(h)}, d_{0}^{(h)}\right), \\
& \beta^{(h)} \mid \Sigma_{\varepsilon}^{(h)}, \lambda^{(h)} \sim \mathcal{N}\left(\beta_{0}^{(h)}, \Sigma_{\varepsilon}^{(h)} \otimes \Omega_{0}^{(h)}\left(\lambda^{(h)}\right)\right),
\end{aligned}
$$

where $\beta^{(h)}$ is the vector containing all the local projection coefficients at horizon $h-$ i.e. $\beta^{(h)} \equiv \operatorname{vec}\left(B^{(h)}\right) . \quad \lambda^{(h)}$ is the hyperparameter that regulates the variance of the coefficients in $\beta^{(h)}$, and thus effectively determines the overall tightness of the priors. The prior mean $\beta_{0}^{(h)}$ is informed by the iterated coefficients of a similarly specified VAR estimated over a pre-sample. For the model in Eq. (8) this writes

$$
\beta_{0}^{(h)}=\operatorname{vec}\left(B_{T_{0}}^{h}\right)
$$

where $B_{T_{0}}^{h}$ is the $h$-th power of the autoregressive coefficients estimated over a pre-sample $T_{0}$, that is then discarded. Intuitively, the prior gives weight to the belief that a VAR can describe the behaviour of economic time series, at least first approximation. ${ }^{24}$

The posterior distribution for the BLP coefficients can then be obtained by combining the priors in Eq. (14) with the likelihood of the data conditional on the parameters, where the autocorrelation of the projection residuals is not taken into account. This

\footnotetext{
${ }^{23}$ If we believed the $\operatorname{VAR}(p)$ to be the correct specification, then LP regressions would have to be specified as $\operatorname{ARMA}(p, h-1)$ regressions. Their coefficients could be then estimated by combining informative priors with a fully specified likelihood (see Chan et al., 2016). If, however, the $\operatorname{VAR}(p)$ were to effectively capture the DGP, it would be wise to discard direct methods altogether.

${ }^{24} \mathrm{An}$ obvious alternative is the generalisation of the standard macroeconomic priors proposed in Litterman (1986), centred around the assumption that each variable follows a random walk process, possibly with drift. Results using this alternative prior are discussed in Appendix B. Also, one could specify a hyperprior distribution for the first autocorrelation coefficients, as a generalisation of Litterman (1986), and conduct inference following the approach in Giannone et al. (2015).
} 
modelling choice has three important implications. First, the priors are conjugate, hence the posterior distribution is of the same Normal inverse-Wishart family as the prior probability distribution. Second, the Kronecker structure of the standard macroeconomic priors is preserved. These two important properties make the estimation analytically and computationally tractable. However, there is a third implication that is the price to pay for the first two: the shape of the true likelihood is asymptotically Gaussian and centred at the Maximum Likelihood Estimator (MLE), but has a different (larger) variance than the misspecified posterior distribution. This implies that if one were to draw inference about $\beta^{(h)}$ - i.e. the horizon- $h$ responses -, from the misspecified posterior distribution, one would be underestimating the variance albeit correctly capturing the mean of the distribution of the regression coefficients.

Müller (2013) shows that posterior beliefs constructed from a misspecified likelihood such as the one discussed here are 'unreasonable', in the sense that they lead to inadmissible decisions about the pseudo-true values, and proposes a superior mode of inference - i.e. of asymptotically uniformly lower risk -, based on artificial 'sandwich' posteriors. $^{25}$ Hence, similarly to the frequentist practice, we conduct inference about $\beta^{(h)}$ by replacing the original posterior with an artificial Gaussian posterior centred at the MLE but with a HAC-corrected covariance matrix:

$$
\begin{aligned}
& \Sigma_{\varepsilon, \mathrm{HAC}}^{(h)} \mid \lambda^{(h)}, \mathrm{y} \sim \mathcal{I} \mathcal{W}\left(\Psi_{\mathrm{HAC}}^{(h)}, d\right) \\
& \beta^{(h)} \mid \Sigma_{\varepsilon, \mathrm{HAC}}^{(h)}, \lambda^{(h)}, \mathrm{y} \sim \mathcal{N}\left(\tilde{\beta}^{(h)}, \Sigma_{\varepsilon, \mathrm{HAC}}^{(h)} \otimes \Omega^{(h)}\right) .
\end{aligned}
$$

This allows us to remain agnostic about the source of model misspecification as in Jordà (2005).

It is worth noticing that BLP IRFs effectively span the space between VARs and local projections. To see this, note that given the prior in Eq. (14), the posterior mean

\footnotetext{
${ }^{25}$ For the purpose of this work, the 'decisions' concern the description of uncertainty around $\beta^{(h)}$ obtained via two-sided equal-tailed posterior probability intervals.
} 
of BLP responses takes the form

$$
B_{\mathrm{BLP}}^{(h)} \propto\left(X^{\prime} X+\left(\Omega_{0}^{(h)}\left(\lambda^{(h)}\right)\right)^{-1}\right)^{-1}\left(\left(X^{\prime} X\right) B_{\mathrm{LP}}^{(h)}+\left(\Omega_{0}^{(h)}\left(\lambda^{(h)}\right)\right)^{-1} B_{\mathrm{VAR}}^{h}\right),
$$

where $X \equiv\left(x_{h+2}, \ldots, x_{T}\right)^{\prime}$, and $x_{t} \equiv\left(1, y_{t-h}^{\prime}, \ldots, y_{t-(h+1)}^{\prime}\right)^{\prime}$. At each horizon $h$, the

relative weight of VAR and LP responses is set by $\Omega_{0}^{(h)}\left(\lambda^{(h)}\right)$ and is a function of the overall level of informativeness of the prior $\lambda^{(h)}$. When $\lambda^{(h)} \rightarrow 0$, BLP IRFs collapse into VAR IRFs (estimated over $T_{0}$ ). Conversely, if $\lambda^{(h)} \rightarrow \infty$ BLP IRFs coincide with those implied by standard LP.

Hence, this formulation allows us to solve the the bias-variance trade-off by estimating IRFs that are an optimal combination of LP and VAR-based IRFs at each horizon. In fact, extending the argument in Giannone, Lenza and Primiceri (2015), we treat $\lambda^{(h)}$ as an additional model parameter for which we specify a Gamma prior probability distribution, and estimate it at each horizon as the maximiser of the posterior likelihood in the spirit of hierarchical modelling. This allows us to effectively balance bias and estimation variance at all horizons, and therefore solve the trade-off in a fully data-driven way. $^{26}$

\section{VAR, LP, and BLP}

We start our empirical exploration by comparing the IRFs estimated using VAR, LP, and BLP in Figure 3. The matrix of contemporaneous transmission coefficients $A_{0}$ is the same in the three cases, and is estimated using our informationally robust series $M P I_{t}$ as an external instrument. ${ }^{27}$ The contractionary monetary policy shock raises the policy rate by $1 \%$ on impact. In the top row, we compare BLP and VAR responses. The bottom

\footnotetext{
${ }^{26}$ See Appendix B for details.

${ }^{27}$ Specifically, if $u_{t}$ and $\xi_{t}$ denote, respectively, the monetary policy shock and the vector of all other shocks, the identifying assumptions are

$$
\mathbb{E}\left[u_{t} z_{t}^{\prime}\right]=\phi, \quad \mathbb{E}\left[\xi_{t} z_{t}^{\prime}\right]=0
$$

where $\phi$ is non singular and $z_{t}$ is the chosen external instrument (see Stock and Watson, 2012; Mertens and Ravn, 2013, for details). An alternative would be to add the instruments to $y_{t}$ in a 'hybrid' VAR (see e.g. Ramey, 2016). Results would coincide, provided that no autocorrelation is present in the instrument, and that the same time span is adopted.
} 
row compares BLP and LP. The vector of endogenous variables, $y_{t}$, includes an index of industrial production, the unemployment rate, the consumer price index, a commodity price index, and the policy rate. The composition of $y_{t}$ is a fairly standard one in empirical macro, and matches those used in both Coibion (2012) and Ramey (2016) for ease of comparability with these studies. It should be stressed that the information set considered is likely to be misspecified due to the small number of variables considered. We choose the 1-year nominal rate as our policy variable as in Gertler and Karadi (2015). Unless otherwise stated, we set the number of lags in both VAR and LP to 12 and use the observations between 1969:01 and 1979:01 as a pre-sample to centre the prior for the BLP coefficients. For the hyperparameters $\lambda^{(h)}$ we specify Gamma hyperpriors with mode equal to 0.4 and a standard deviation that is a Logistic function of the forecast horizon. All variables are monthly, and the estimation sample goes from 1979:01 to 2014:12. ${ }^{28}$

A few features emerging from this comparison are worth noticing. Overall, over this sample, results are qualitatively consistent across methods: the policy rate returns to equilibrium level within the first two quarters after the shock, and real activity and prices contract under the three modelling alternatives. The length of the sample used, combined with the small size of $y_{t}$, also limits the erratic nature of LPs. Because many sample observations are available at each horizon, the estimates of projection coefficients are relatively well behaved in this instance. However, notwithstanding the relatively long sample available for the analysis, LP responses quickly become non-significant after the first few horizons. The width of $90 \%$ LP confidence bands dwarfs those of BLP responses, which are instead comparable to those of the VAR (BLP responses are the same in the top and bottom row of the figure). In this case the shape of LP and VAR responses displayed in Figure 3 is qualitative similar. This is not necessarily the case, as results in Sections 4 and 5 show.

VAR responses are, by construction, the smoothest. Based on the same one-stepahead model iterated forward, VAR responses naturally also have tighter bands than

\footnotetext{
${ }^{28} \mathrm{~A}$ detailed description of the method is in Appendix B. See Table C.2 in Appendix C for details on series included. The resilience of BLP responses to the chosen lag length is plotted in Figure C.2 in Appendix C. Results are also robust to the lag length of the VAR prior (not shown).
} 
FIGURE 3: VAR, LP AND BLP RESPONSES
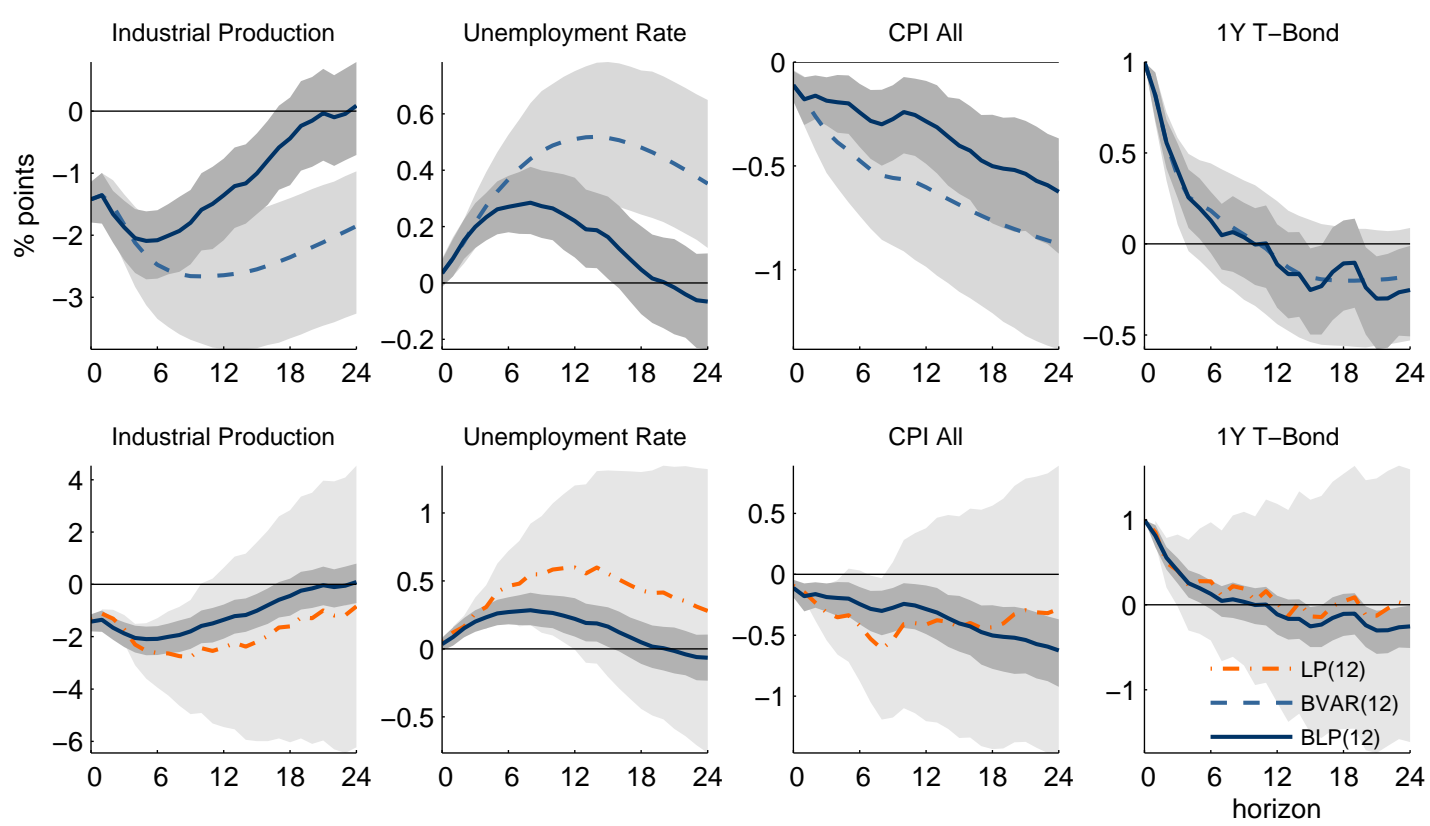

TOP ROw: VAR (teal, dashed) and BLP (blue, solid) impulse responses. BOTTOM ROw: LP (orange, dash-dotted) and BLP (blue, solid) impulse responses. Shaded areas are 90\% posterior coverage bands.

LP do - Eq. (13). This feature, however, also results in VARs implying stronger and more persistent effects than BLPs (and LPs) do. Conditional on a very similar path for the policy rate response, BLP-IRFs tend to revert to equilibrium faster than VAR-IRFs do, and tend to imply richer adjustment dynamics. This may indicate that some of the characteristics of the responses of the VAR may depend on the dynamic restrictions imposed by the iterative structure, rather then being genuine features of the data. The blue bars in Figure 4 display the optimal prior shrinkage hyperparameters that maximise $p\left(\lambda^{(h)} \mid \mathrm{y}^{(h)}\right), \mathrm{y}^{(h)}=\operatorname{vec}\left(\mathrm{Y}^{(h)}\right), Y^{(h)} \equiv\left(y_{p+1+h}, \ldots, y_{T}\right)^{\prime}$ for $h=2, \ldots, 24$ in the BLP responses in Figure 3. The VAR prior is optimally loosened as the horizon increases, suggesting that the data tend to progressively deviate from the VAR responses. In particular, we observe that BLP peak responses are registered significantly earlier than VAR peaks, and are often realised within the first year after the shock. This again holding an equivalent shape for the policy rate response across the two methods. The discussion in Section 5 explores the deviation from the VAR prior further and shows 


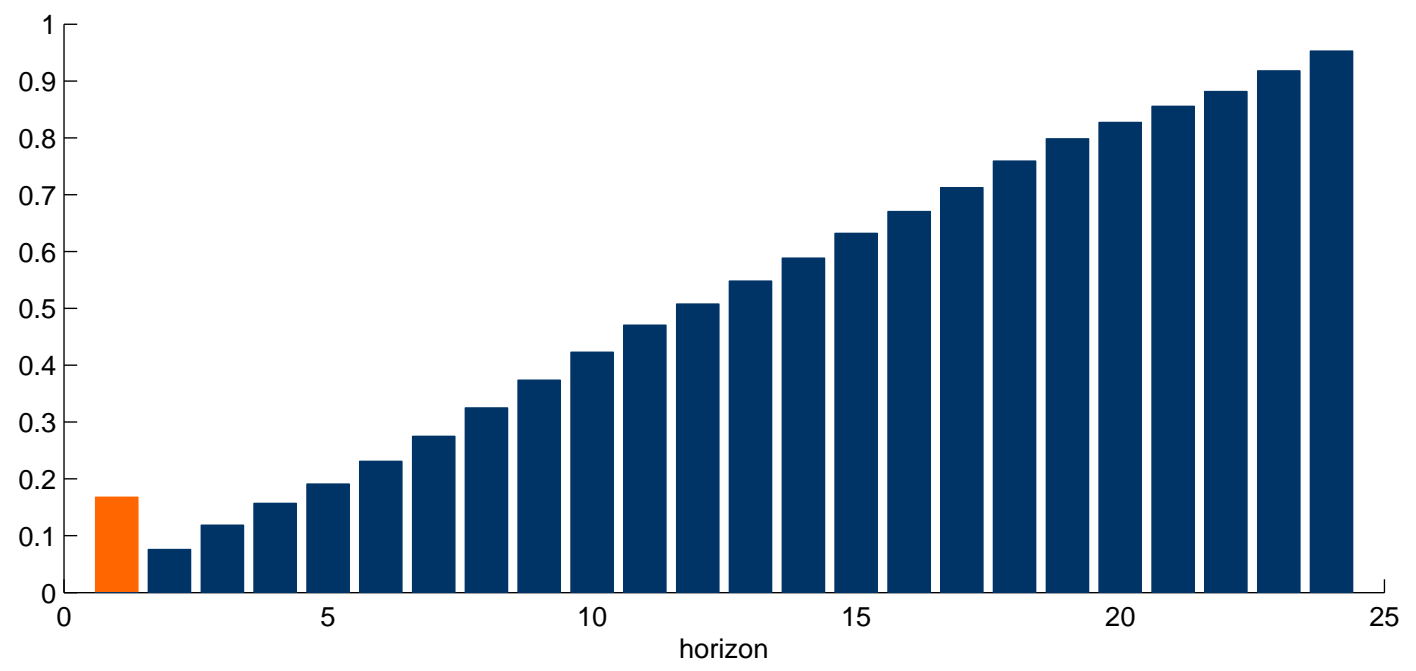

Note: The orange bar is the optimal shrinkage of the Litterman (1986) prior for the VAR coefficients at $h=1$. Blue bars are for the optimal tightness of the VAR prior for BLP coefficients for $h>1$.

that, again holding everything else fixed, the iterative nature of VAR responses can at times contribute to the emergence of puzzles which are absent in BLP responses.

\section{The Transmission of Monetary Disturbances}

Monetary policy decisions are thought to affect economic activity and inflation through several channels, collectively known as the transmission mechanism of monetary policy. In this section we report our empirical results on the effects of monetary policy shocks on a large number of variables, and provide evidence compatible with the activation of several of the potential channels that have been discussed in the literature (see e.g. Mishkin, 1996; Bernanke and Gertler, 1995, for a review). ${ }^{29}$ As before, monetary policy shocks are identified by using the $M P I_{t}$ instrument defined in Section 1.1. Results, in the form of dynamic responses and obtained using the BLP approach, are presented in Figures 5 to 7 . Unless otherwise specified, responses are from a $B L P(6)$ estimated from

\footnotetext{
${ }^{29}$ Increasing the conditioning set of variables is likely to reduce the model misspecifications by including variables relevant to the transmission of disturbances. Also, it allows for a landscape view of the effects of monetary shocks.
} 
1979:01 to 2014:12. As in the previous section, prior beliefs for the local projections are obtained from a $\operatorname{VAR}(12)$ estimated over the pre-sample 1969:01 - 1979:01. $A_{0}$ is estimated over the sample common to the external instrument $\left(M P I_{t}\right)$ and the VAR innovations. The shock is normalised to raise the 1-year rate (policy variable) by $1 \%$. Shaded areas are $90 \%$ posterior coverage bands. ${ }^{30}$

In line with results shown in previous sections, a contractionary monetary policy shock is unequivocally and significantly recessionary also in a larger model (Figure 5). Tight monetary policy depresses real activity and reduces prices. Production, capacity utilisation, and inventories all contract, with peak effects often realised within the first year following the shock. The labour market is also significantly and negatively affected, but with delay. Both the unemployment rate and total hours worked display muted responses on impact, with peak effects realised after two quarters. This is suggestive of the presence of frictions in the labour market, such as contractual obligations, which delay the adjustments. Wages too take about a quarter before they start shrinking. Conversely, the contraction in prices, whether measured using the CPI index or the personal consumption deflator, is typically more sudden, with non persistent effects. In line with models of imperfect information and model in which a number of both real and nominal frictions are at play (e.g. Smets and Wouters, 2007), prices do not fully adjust on impact, but keep sliding over a few months to reach a negative peak of about half a percentage point within the first six months after the shock.

Real income suffers a prolonged contraction that survives for over a year after the shock. Consumption and investment spending both contract, dragging aggregate demand down. Real durable consumption increases slightly on impact, to shrink by about $2 \%$ after the first quarter. The initial response of real durable consumption is likely due to the stickiness of consumers' plans on durable goods, combined with the drop in prices. Nondurable consumption seems to be less affected by the shock.

The shock induces a significant impact rotation of the yield curve whereby for a $1 \%$

\footnotetext{
${ }^{30}$ We set the number of LP lags to 6 to reduce the number of parameters to be estimated in this large specification, hence controlling for the risk of over parametrisation in LP. As previously discussed, results are robust to the lag length. VAR and LP responses are displayed in Appendix C. Variables used are listed in Table C.2.
} 
Figure 5: The Effects of Monetary Policy Shocks
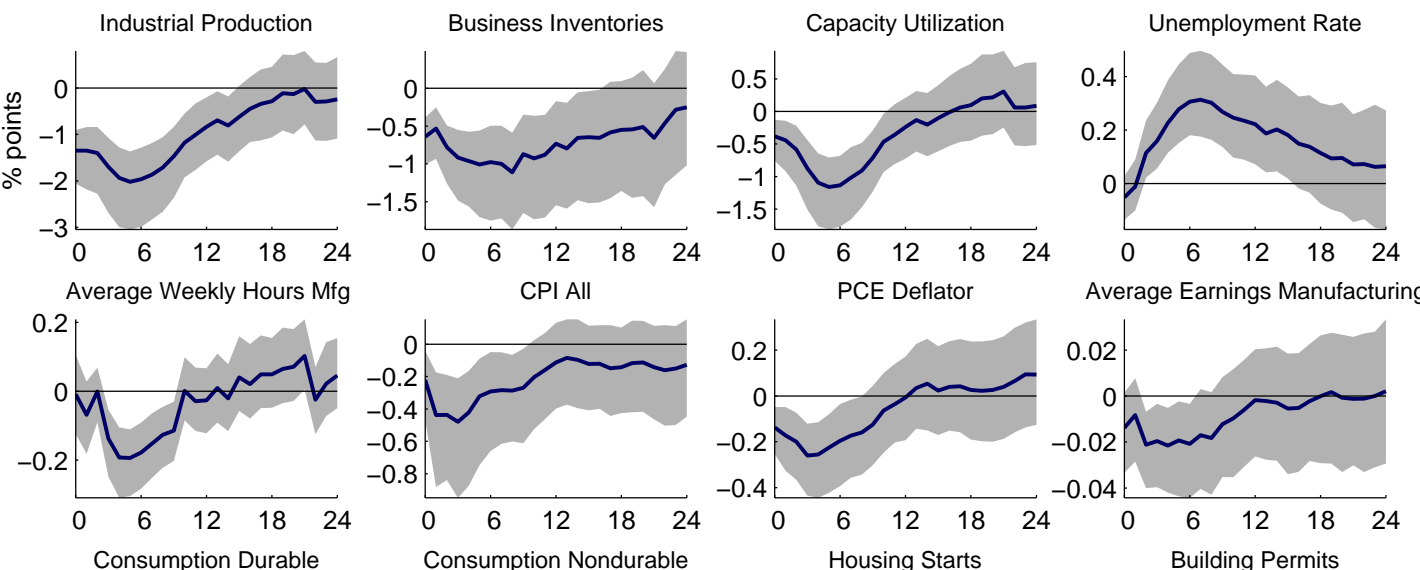

Average Earnings Manufacturing
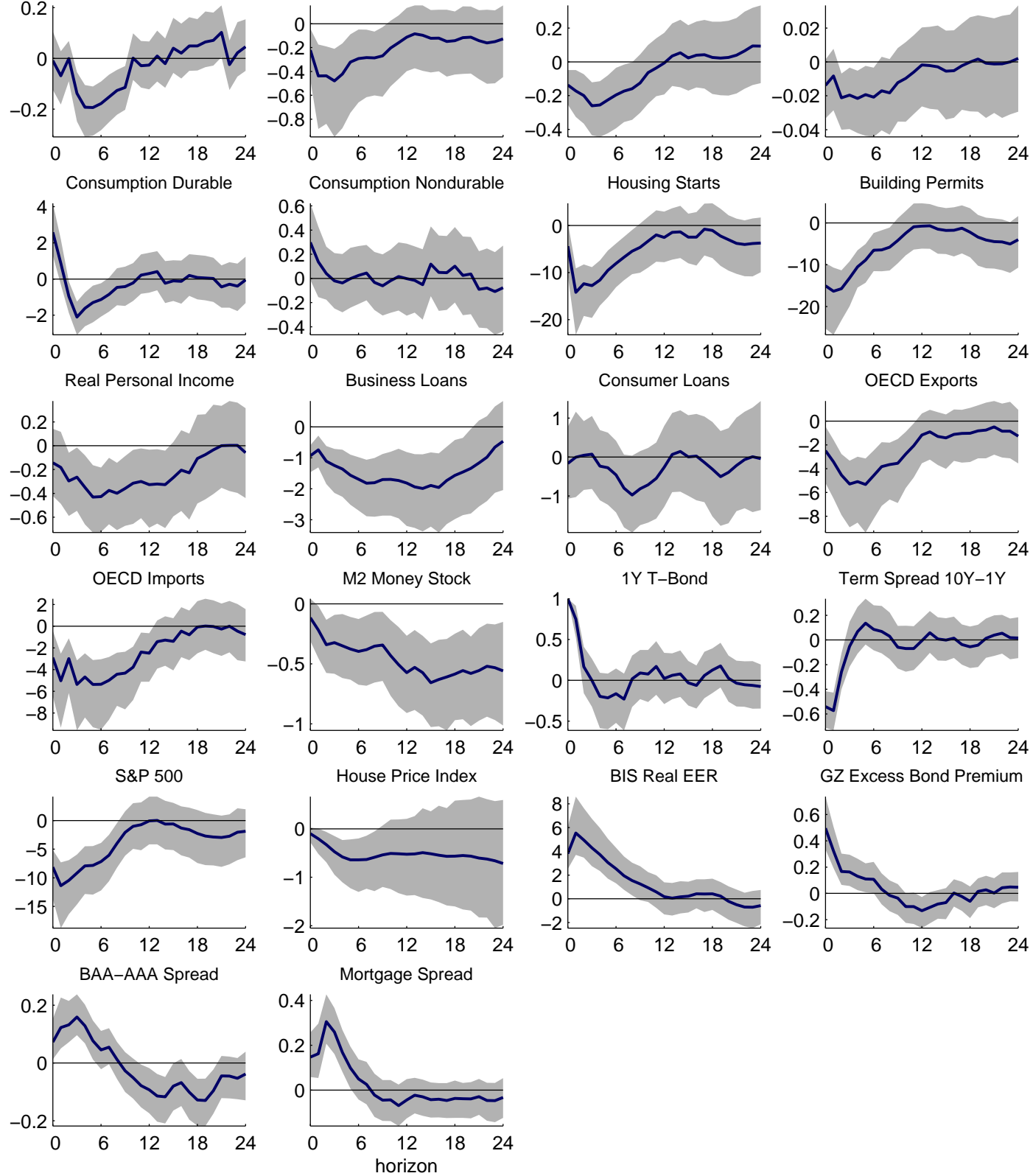

Note: BLP responses to a contractionary monetary policy shock. Shock identified with the MPShock series and normalisedto induce a 100 basis point increase in the 1-year rate. Sample 1979:01 - 2014:12. $B L P(6)$ with $V A R(12)$ prior over 1969:01 - 1979:01. Shaded areas are 90\% posterior coverage bands. VAR and LP responses in Figure C.3. 
Figure 6: Yield Curve Response to MP Shocks
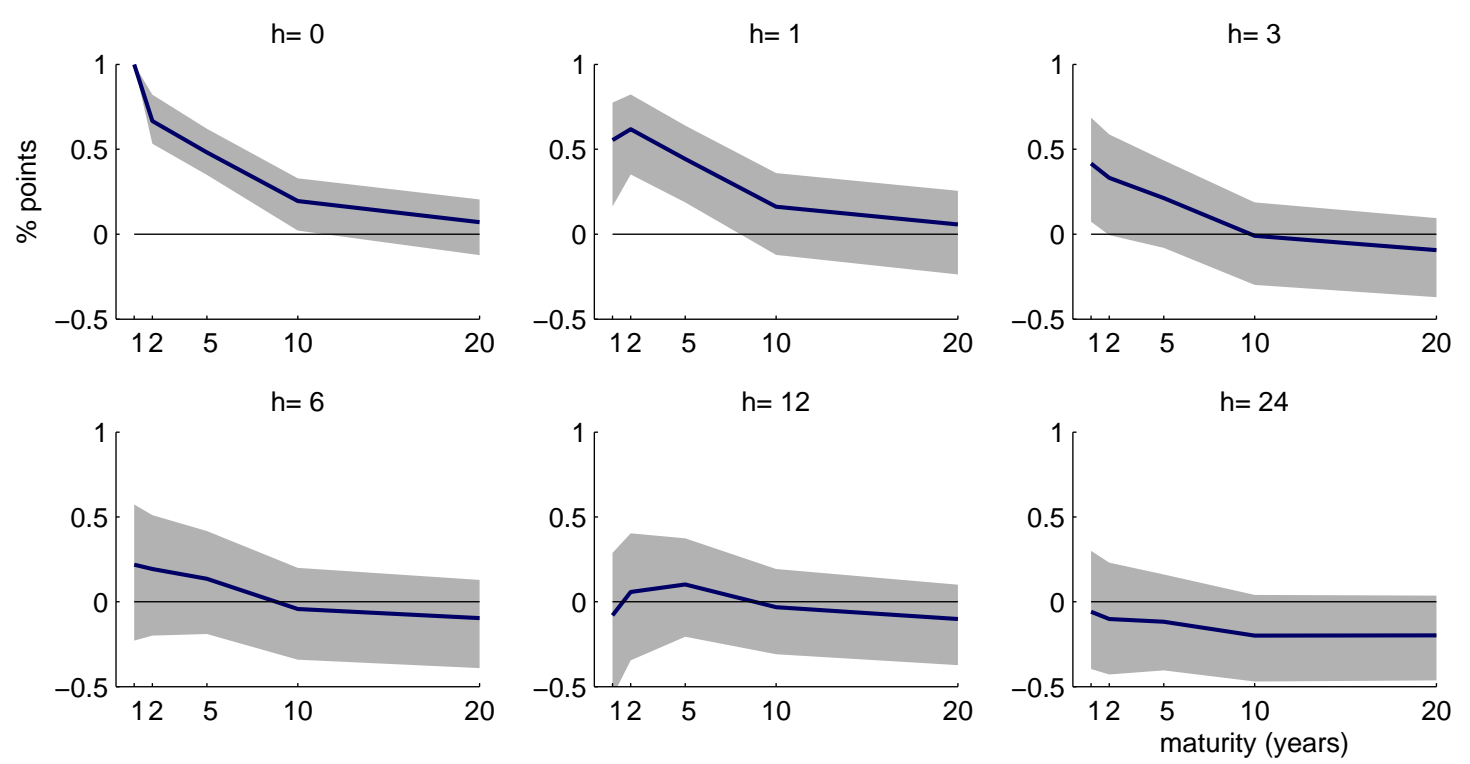

Note: BLP responses to a contractionary monetary policy shock. Shock identified with the MPShock series and normalised to induce a 100 basis point increase in the 1-year rate. Sample 1979:01 - 2014:12. $B L P(6)$ with $V A R(12)$ prior over 1969:01 - 1979:01. Shaded areas are 90\% posterior coverage bands. VAR and LP responses in Figure C.4.

rise in the 1-year rate, we see up to a 50 basis point contraction in the term spread. Both responses are sudden and temporary: the increase in the policy variable dissipates completely within the first two quarters. We explore further the details of the responses of interest rates at different maturities in Figure 6. Here each subplot is horizon-specific, and maturities (in years) are reported on the horizontal axes. All interest rates rise on impact with responses that are both smaller in magnitude and quicker to revert to trend the higher the maturity. The long end of the yield curve (20-year rate) does not move, in line with what expected for the effects of a temporary monetary contraction (see also discussion in Romer and Romer, 2000; Ellingsen and Soderstrom, 2001). All the curve's responses are not significant at the two-year horizon, with a slightly negative median response. This could be taken as a weak indication of the the endogenous reaction of the central bank to the swift weakening of the economic outlook.

To better understand the strong real effects discussed above, particularly in light of 
the relatively muted movements of the long end of the curve, we investigate the responses of financial and credit variables. The effects reported in Figure 5 are consistent with a deterioration of household wealth working through both a reduction of labor income, and of financial wealth. The decline in financial wealth is likely the product of negative valuation effects triggered by the contraction in asset prices. The reaction of asset prices is spread across different asset classes. House prices fall and the stock market suffers important losses. Housing investment collapse, with immediate falls well beyond the 10\% mark. These effects have a detrimental impact on both equity and assets valuation, making collaterals become more costly.

The strong effects on both real activity and output are likely magnified by the reaction of credit and financial markets, consistently with the 'financial accelerator' hypothesis and the existence of a credit channel for monetary policy (Bernanke et al., 1999). Lending dips significantly, particularly so for businesses. This is consistent with a number of possible mechanisms, all of which find some degree of support. On the one hand, it is the supply of credit that shrinks. Bank lending can contract for several reasons. First, contractionary monetary policy reduces cash flows and increases indirect expenses, with direct effects on the amount of new loans granted. Second, through its effect on asset prices, contractionary policy has a direct valuation effect on lenders' balance sheets. Higher rates mean lower net margins, and thus lower profits going forward. Also, the drop in asset prices can imply a reduction in bank capital which may in turn induce deleveraging in the form of less credit supplied (see Boivin et al., 2010). On the other hand, however, the demand for credit may slow down due to borrowers being less willing to undertake new investment projects. One important reason why this may be the case is that borrowing costs rise. Following the shock, corporate bond spreads and premia (the excess bond premium of Gilchrist and Zakrajšek, 2012) both significantly rise on impact, and remain high for about half a year. This is consistent with a surge in the external finance premium, that is, the wedge between external (e.g. equity/debt issuance) and internal (e.g. retained earnings) funding costs (see Bernanke and Gertler, 1995; Gertler and Karadi, 2015). Opposite to what discussed above, this mechanism operates through the borrowers' balance sheet: the lower the borrower's net worth, the 
higher the finance premium. Variations in the net worth affect investment and spending decisions, with magnifying effects on borrowing costs, real spending and real activity. The mechanism affects both businesses and households alike. The fall in house prices, the contraction in housing investments, and the sharp and sudden increase in mortgage spreads all concur to curtail lending to households as well. ${ }^{31}$

After the shock, the dollar appreciates suddenly, and in real terms, against a basket of foreign currencies. This appears to also activate an exchange rate channel. In fact, exports become more costly due to the appreciation, and contract as a result. Notwithstanding the stronger purchasing power sustained by the appreciation of the domestic currency, the ensuing recession, accompanied by a contraction of internal demand, also makes imports contract, and significantly so. Overall, the external position tends to deteriorate slightly over the first year.

While the sign and magnitude of the effects discussed so far is largely consistent with standard macroeconomic theory, the BLP approach allows us to uncover effects with an average duration that is significantly shorter than what was previously reported. BLPs, optimised at each horizon to better model variables' responses, lack the persistence that the iterative nature of the VAR approach forces on the estimated IRFs (see also discussion in Section 2 and Figure C.3 in Appendix C for a direct comparison). Figure 5 shows that, with the exception of very few cases, all variables are back to trend levels within a year after the shock. This can have potentially important implications for the policy debate, and in particular for what concerns the adequateness of the policy horizon, the duration of which is typically calibrated based on VAR evidence.

Finally, we turn to the responses of private sector expectations, in Figure 7. As observed in Woodford (2011), modern monetary policy is not simply a matter of controlling overnight interest rates, but rather one of shaping market expectations of the forward path of interest rates, inflation and income. To study how agents' expectations respond to policy changes, we augment a set of variables relevant for the analysis of the standard

\footnotetext{
${ }^{31}$ The response of mortgage spreads is calculated over a shorter sample (1990:01 - 2014:12) due to data being available only since the late seventies. The observations from 1979:01 to 1989:12 inform the BLP prior in this case.
} 
Figure 7: Response of Expectations to MP Shocks
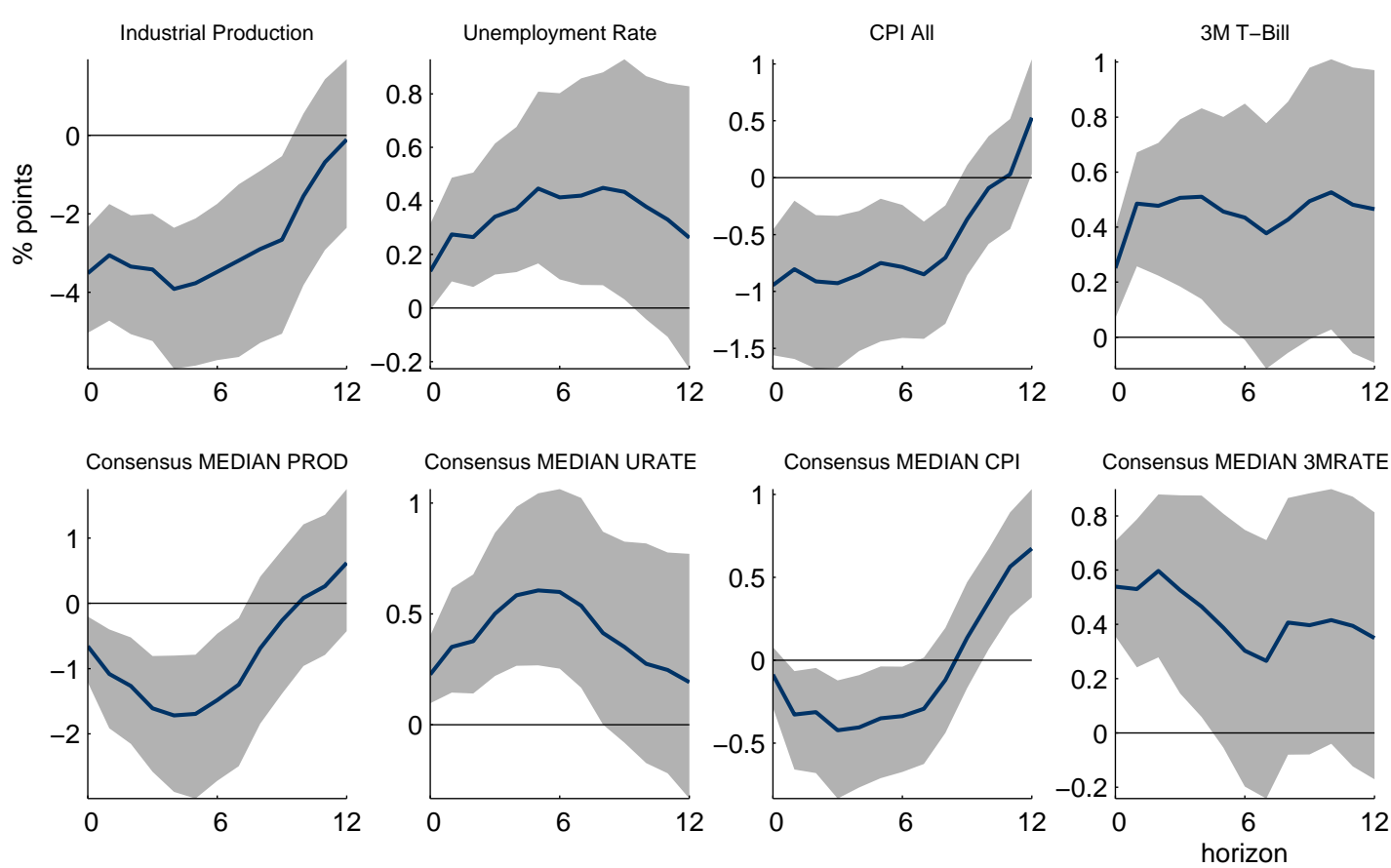

Note: BLP responses to a contractionary monetary policy shock. Shock identified with the MPShock series and normalised to induce a 100 basis point increase in the 1-year rate. Sample 1999:01 - 2014:12. $B L P(6)$ with $V A R(12)$ prior over 1993:01 - 1999:01. Shaded areas are 90\% posterior coverage bands. VAR and LP responses in Figure C.5.

interest rate channel with Consensus Economics forecast data. ${ }^{32}$ Each month, experts from public and private economic institutions - mostly investment banks and economic research institutes -, are surveyed about their projections for the main macroeconomic and financial variables. Neither central banks nor governments participate in the survey. Survey respondents contribute fixed-event forecasts relative to realisations in the current and the following calendar year. To avoid issues relative to the forecast horizon shrinking as the survey date approaches the end of each year, we approximate median one-year-ahead forecasts as a weighted average of median fixed-event annual forecasts. ${ }^{33}$

\footnotetext{
${ }^{32}$ Consensus Economics forecasts are only available since 1993 . To address issues related to the short sample, and hence the small number of observations that are available to consistently estimate LP coefficients, we only calculate BLP IRFs over a 12-month horizon. Responses are estimated using data from 1999:01 - 2014:12. The years from 1993 to 1999 inform the BLP prior.

${ }^{33}$ Specifically, the rolling twelve-month-ahead forecasts are computed as

$$
F_{t} x_{t+12}=\frac{h}{12} F_{t} x_{t+h}+\frac{12-h}{12} F_{t} x_{t+12+h}
$$
}


Industrial production and CPI are converted to year-on-year growth rates for ease of comparison, to match the forecasts units. Agents' median expectations adjust in line with the deteriorating fundamentals. It is important to stress here that this result follows only once the effects of signalling are appropriately accounted for. Conversely, as documented in Campbell et al. (2012, 2016) and Nakamura and Steinsson (2013), identifying disturbances using instruments that do not control for such a transfer of information makes expectations adjust in the 'wrong' direction, as agents interpret the interest rate move as an endogenous policy reaction to stronger than expected economic developments. Consistent with theory, we find instead that as a result of a contractionary monetary policy shock agents expect both inflation and output to slow down over time. In particular, forecasts for prices, production, consumption and investment are all revised downward, while the opposite holds for unemployment forecasts. Interestingly, consistent with the literature on the presence of informational frictions, we find that while the direction of the revision of expectation is in line with a recessionary outlook, forecasters revise their assessment in a sluggish fashion. Notably, while production falls by $4 \%$ in annual terms, the movement in the forecasts is more gradual over the horizons. Annual CPI inflation drops by $1 \%$, while agents revise their forecasts gradually downward. This type of behaviour is compatible with information being only partially and slowly processed over time. Conversely, with full information forecasts should immediately adjust to shocks, and by the same amount as the variable being forecasted (see discussion in Coibion and Gorodnichenko, 2012).

\section{Puzzles Revisited}

In this section we document how much of the lack of stability reported in previous studies can be explained by the compounded effects of the assumptions of full information that are commonly made when identifying monetary policy shocks, and the use of severely misspecified models for the estimation of the dynamic responses. To disen-

where $F_{t} x_{t+h}$ is the $h$-month-ahead median forecast of variable $x$ made at time $t$. The forecasts produced by the respondents are $\left\{F_{t} x_{t+h}, F_{t} x_{t+12+h}\right\}$ with horizons $h \in\{1,2, \ldots, 12\}$ and $h+12$ months (see Dovern et al., 2012). 
TABle 3: Reliability of ALternative instruments

\begin{tabular}{|c|c|c|c|c|c|c|c|c|c|}
\hline \multirow[b]{2}{*}{$F$ statistic } & \multicolumn{3}{|c|}{$M P I_{t}$} & \multicolumn{3}{|c|}{$F F 4_{t}^{G K}$} & \multicolumn{3}{|c|}{$M P N_{t}$} \\
\hline & 9.571 & {$[5.581$} & $11.256]$ & 13.147 & {$[5.354$} & $18.954]$ & 61.167 & {$[49.090$} & 68.549] \\
\hline reliability & 0.074 & {$[0.056$} & $0.081]$ & 0.070 & {$[0.038$} & $0.094]$ & 0.267 & {$[0.223$} & $0.294]$ \\
\hline
\end{tabular}

Note: TOP ROW: F statistics of the stage-1 regression of the reduced-form innovations on the instrument. воттом Row: reliability of the instrument. $90 \%$ confidence intervals in square brackets.

tangle the contributions, we compare responses to shocks obtained either by using the same empirical specification and changing the external instrument, or using the same (informationally-robust) instrument and changing the empirical specification. All other features are kept fixed and in line with the ones adopted in the previous sections.

\subsection{The Role of Different Identifying Assumptions}

The IRFs in Figure 8 depict responses obtained using different identifications and the same empirical specification (BLP). The contractionary monetary policy shock is normalised in all cases to induce a $1 \%$ increase in the policy rate on impact, and the sample used for the estimation is 1979:1 to 2014:12. The difference among the IRFs reported in the charts lies in the informational assumptions made in order to identify the shock. The dashed teal lines report the responses to a monetary policy shock identified using the average market surprises surrounding the policy announcements as in Gertler and Karadi (2015) - FF4t $4_{t}^{G K}$. The orange (dash-dotted) lines, on the other hand, are responses to shocks identified using the narrative instrument of Romer and Romer (2004) - MPN . Lastly, the solid blue lines indicate the effects of a monetary disturbance identified using the informationally robust instrument proposed in Section 1.1, $M P I_{t}$. In each case, we use these series as external instruments for the identification. ${ }^{34}$

A few features are noteworthy. First, both the narrative and Gertler and Karadi (2015)'s high-frequency instruments imply a much more persistent response for the policy rate compared to our new measure. The response of the policy rate is still signi-

\footnotetext{
${ }^{34}$ In each case, we use the common sample between the VAR innovations and the external instrument to estimate the relevant entries of $A_{0}$.
} 
FiguRE 8: BLP RESPONSES TO MONETARY POLICY SHOCK UNDER DIFFERENT IDENTIFICATIONS
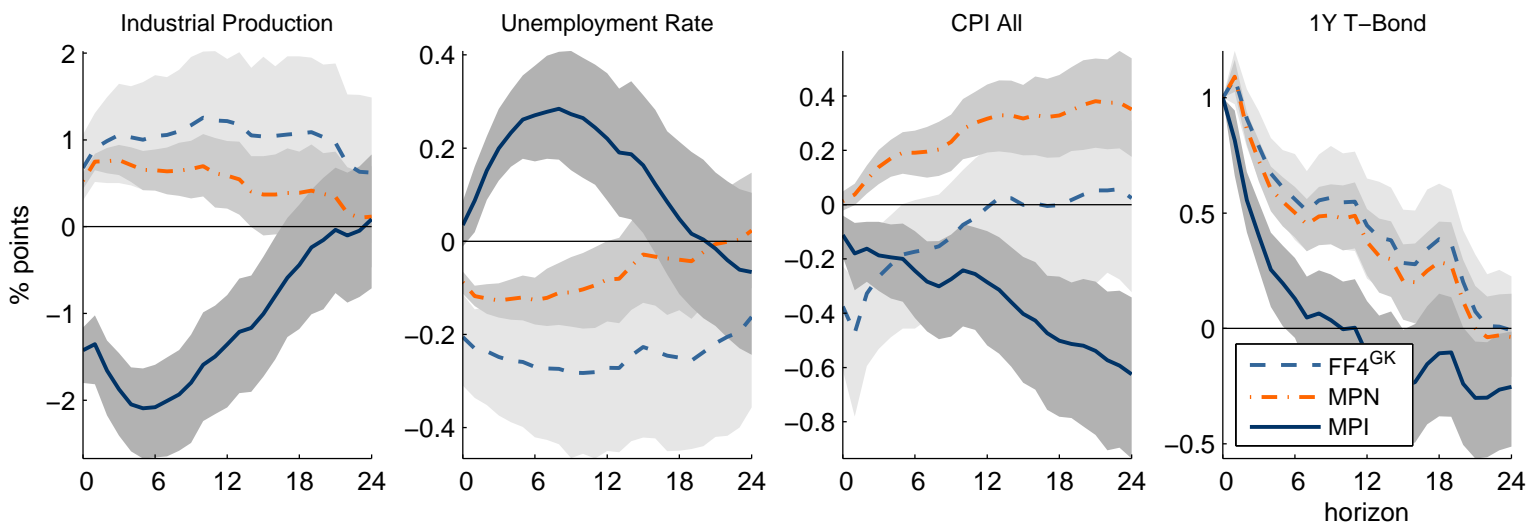

Note: Shock identified with Gertler and Karadi (2015)'s average monthly market surprise (teal, dashed), extended narrative measure of Romer and Romer (2004) (orange, dash-dotted), informationally robust $M P I_{t}$ series (dark blue lines). The shock is normalised to induce a 100 basis point increase in the 1-year rate. Sample 1979:1 - 2014:12. BLP(6) with VAR(12) prior over 1969:01 - 1979:01. Shaded areas are $90 \%$ posterior coverage bands.

ficant 20 months after the shock, and is nearly identical in the two cases. Second, and quite crucially, both instruments induce significant and long lived real activity puzzles. Third, while the average market surprise elicits an immediate contraction in prices, the narrative series triggers a sustained price puzzle. Similar evidence is documented in Ramey (2016) and Miranda-Agrippino (2016). Consistent with standard macroeconomic theory, on the other hand, our instrument identifies a contractionary monetary policy shock that induces a contraction in output, a rise in unemployment, and a reduction in prices. In a full-information rational expectation setting, the use of either instrument should deliver identical results. Conversely, and holding fixed the specification of the VAR/BLP, the heterogeneity of the responses in Figure 8 can be thought of as an indirect indication of the different informational content of the three instruments. In particular, responses seem to confirm that both the narrative and high-frequency instruments are autocorrelated and not orthogonal to the state of the economy (see Section 1.3). As discussed, the signalling channel of monetary policy - i.e. the information transferred by the central bank to private agents via policy actions - can contaminate high-frequency instruments thereby inducing empirical puzzles. Finally, it is worth mentioning that the 
Figure 9: VAR, BLP AND LP RESPONSES ACROSS SUBSAMPLES
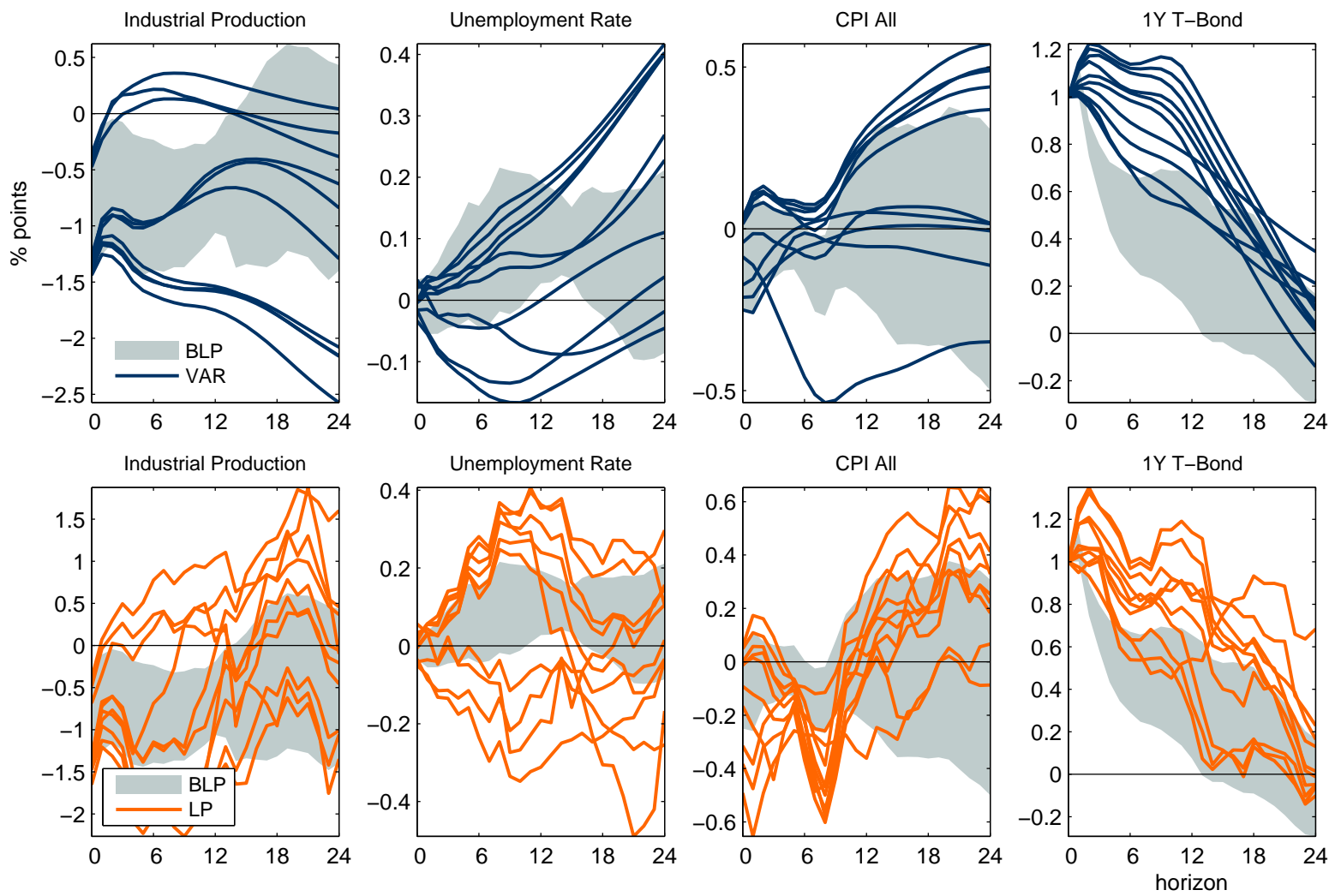

Note: TOP Row: $\operatorname{VAR}(12)$ (blue, solid), and BLP(12) (grey, area) responses. вотtom Row: LP(12) (orange, solid), and BLP(12) (grey, area) responses. Subsamples 1981:2005, 1982:2006, ..., 1990:2014.

heterogeneity of the responses, and relative puzzling outcomes, are a strong indication of the contamination of the high-frequency and the narrative instrument by other macroeconomic shocks. While this casts a shade on the exogeneity of the instruments, it can explain the statistical results on their relevance (Table 3).

\subsection{The Role of Different Modelling Choices}

Figure 9 compares the responses obtained using VAR, LP and BLP over a set of 24-year subsamples from 1981 to 2014, using our novel instrument. The information set used in this exercise is reduced by choice to the core of the macroeconomic variables virtually employed in all the empirical applications in the literature. As such, it discards many variables potentially important in the transmission of monetary policy shocks in the 
Figure 10: VAR, BLP AND LP RESPONSES ACROSS SUBSAMPLES
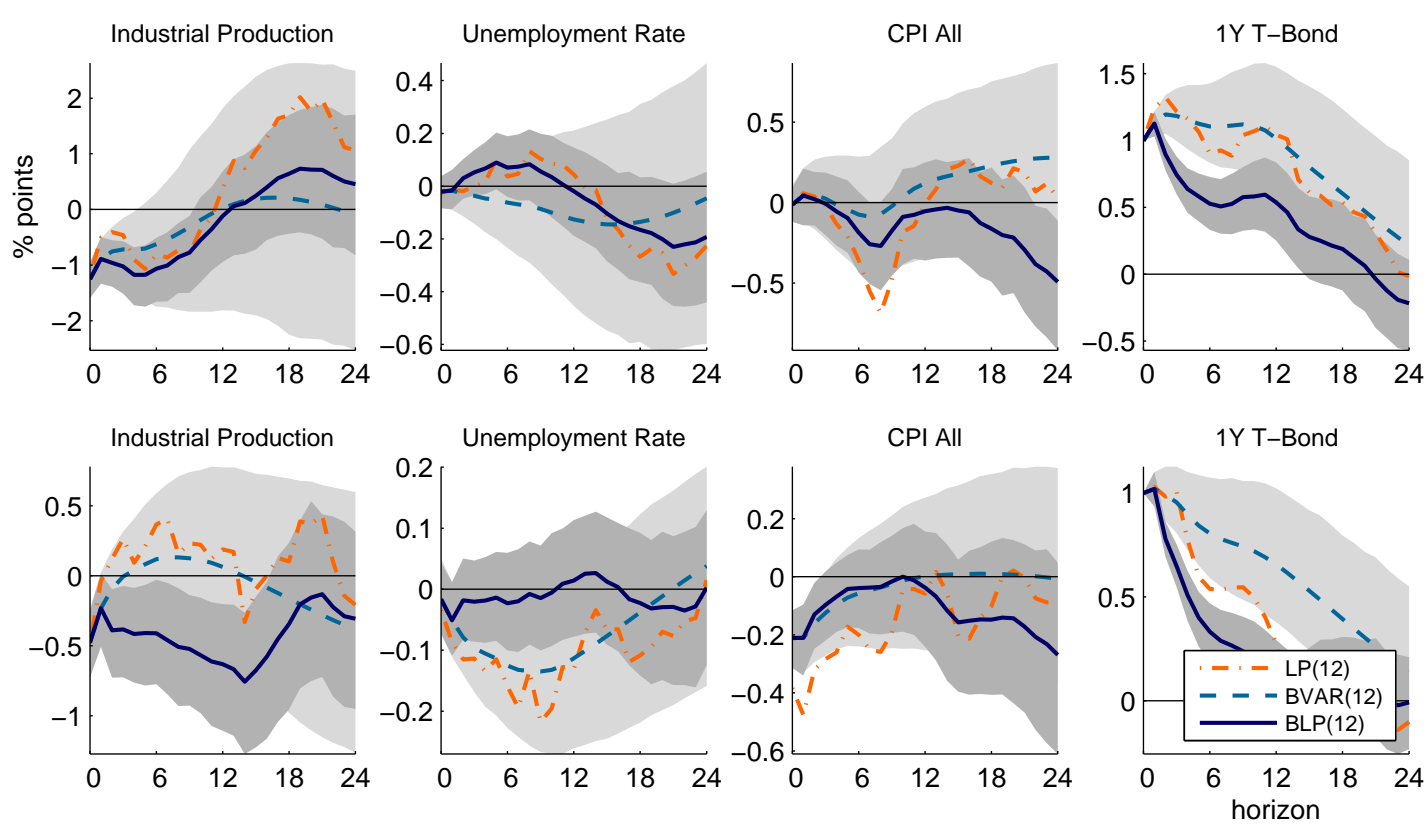

Note: $B L P(12)$ with $\operatorname{VAR}(12)$ prior (blue, solid), $\operatorname{VAR}(12)$ (teal, dotted) and $L P(12)$ (orange, dashdotted) responses to a contractionary monetary policy shock. TOP ROW: estimation sample 1990:01 2012:12, pre-sample 1969:01 - 1979:12. воттом ROW: estimation sample 1983:01 - 2007:12, pre-sample 1969:01 - 1982:12.

economy, hence amplifying the information set misspecification of the system. ${ }^{35}$ This specification is helpful to assess how different methods cope with potentially severely misspecified models and short samples. Indeed, it can be thought of as a severe test on the robustness of BLP with respect to model bias. In all cases $A_{0}$ is estimated using the $M P I$ series as an external instrument. The blue lines in the top row of the figure are the VAR responses for each of the subsamples. Similarly, the orange lines in the bottom row are LP responses in each of the subsamples. Conversely, the grey areas in both rows cover all the space occupied by the BLP responses in those same sub-periods. We abstract from estimation uncertainty.

Again, a few elements are worth attention. First, the responses of the policy variable are markedly more persistent when estimated with a VAR. In a number of occasions,

\footnotetext{
${ }^{35}$ With respect to the previous specification, here we drop the commodity price index that has large instabilities over the subsamples considered, and could appear as a confounding factor in the analysis.
} 
moreover, the policy rate stays above the $1 \%$ impact increase for over a year. Second, the reaction of real variables to a monetary contraction is decisively recessionary for BLP. The same does not hold for VAR responses which, in some cases, lead to puzzling expansionary effects, with production increasing and unemployment decreasing after the shock. Additionally, even when of the 'correct' sign, some of the VAR responses for these two variables seem to imply equally puzzling exploding behaviours. Lastly, we note that BLP responses for prices display a less clear-cut interpretation over longer horizons. Conversely, VAR responses in equivalent subsamples imply strong price puzzles. Turning the attention to the bottom row of the figure, we see how the erratic nature of LP responses is exacerbated by the small samples used. In particular, we note that LP too can lead to puzzling responses for both production and unemployment in some instances. In a further robustness check, we test the behaviour of BLP focusing on two subsamples which have been recognised as being particularly problematic because of either output or price puzzles (see e.g. Ramey, 2016). In the top row of Figure 10, IRFs are estimated over the period 1990:01 - 2012:12, while those in the bottom row refer to the years 1983:01 - 2007:12. In both cases BLP responses register a contraction of output and prices, and a muted response of unemployment. Importantly, the same does not hold for both VAR and LP IRFs. Our experiments confirm that BLP can sensibly reduce the impact of compounded biases over the horizons, effectively dealing with model misspecifications.

\section{Conclusions}

What are the effects of monetary policy? Despite being one of the central questions in macroeconomics, and the numerous theoretical and methodological advances, the discussion on the effects of monetary policy appears to be still surrounded by a substantial degree of uncertainty. In fact, not just the magnitude and the significance, but even the sign of the responses of crucial variables - prices and output being a prime example - depends on the chosen identification strategy, the sample period, the information set considered, and the details of the model specification. 
This paper helps rationalising unstable and puzzling previous results by using a novel flexible econometric model that optimally bridges between standard VARs and the Local Projection approach, and an identification strategy coherent with the intuitions stemming from models of asymmetric and imperfect information.

Results proposed show that following a monetary tightening economic activity and prices contract, lending to consumers and businesses cools down, and expectations move in line with fundamentals. Moreover, the currency appreciates, and equity prices fall. Finally, the slope of the yield curve flattens, borrowing costs rise and so do corporate spreads. These effects are both sizeable and persistent, suggesting that monetary policy is a powerful tool for both economic stabilisation and financial stability. These findings are robust to a number of severe tests.

\section{References}

Admati, Anat R, "A Noisy Rational Expectations Equilibrium for Multi-asset Securities Markets," Econometrica, May 1985, 53 (3), 629-57.

Andrade, Philippe and Hervé Le Bihan, "Inattentive professional forecasters," Journal of Monetary Economics, 2013, 60 (8), 967-982.

Barakchian, S. Mahdi and Christopher Crowe, "Monetary policy matters: Evidence from new shocks data," Journal of Monetary Economics, 2013, 60 (8), 950-966.

Barnichon, Régis and Christian Brownlees, "Impulse Response Estimation By Smooth Local Projections," CEPR Discussion Papers 11726, C.E.P.R. Discussion Papers December 2016.

- and Christian Matthes, "Gaussian Mixture Approximations of Impulse Responses and the Nonlinear Effects of Monetary Shocks," Working Paper 16-8, Federal Reserve Bank of Richmond March 2014.

Bernanke, Ben S and Alan S Blinder, "The Federal Funds Rate and the Channels of Monetary Transmission," American Economic Review, September 1992, 82 (4), 901-21.

Bernanke, Ben S. and Kenneth N. Kuttner, "What Explains the Stock Market's Reaction to Federal Reserve Policy?," The Journal of Finance, 2005, 60 (3), 1221-1257.

- and Mark Gertler, "Inside the Black Box: The Credit Channel of Monetary Policy Transmission," Journal of Economic Perspectives, Fall 1995, 9 (4), 27-48.

_, , , and Simon Gilchrist, "The financial accelerator in a quantitative business cycle framework," in J. B. Taylor and M. Woodford, eds., Handbook of Macroeconomics, Vol. 1 of Handbook of Macroeconomics, Elsevier, 1999, chapter 21, pp. 1341-1393. 
Blinder, Alan S., Michael Ehrmann, Marcel Fratzscher, Jakob De Haan, and David-Jan Jansen, "Central Bank Communication and Monetary Policy: A Survey of Theory and Evidence," Journal of Economic Literature, December 2008, 46 (4), 910-45.

Boivin, Jean, Michael T. Kiley, and Frederic S. Mishkin, "How Has the Monetary Transmission Mechanism Evolved Over Time?," in Benjamin M. Friedman and Michael Woodford, eds., Handbook of Monetary Economics, Vol. 3 of Handbook of Monetary Economics, Elsevier, 2010, chapter 8, pp. 369-422.

Braun, Phillip A. and Stefan Mittnik, "Misspecifications in vector autoregressions and their effects on impulse responses and variance decompositions," Journal of Econometrics, October 1993, 59 (3), 319-341.

Caldara, Dario and Edward Herbst, "Monetary Policy, Real Activity, and Credit Spreads: Evidence from Bayesian Proxy SVARs," Finance and Economics Discussion Series 2016-049, Board of Governors of the Federal Reserve System (U.S.) May 2016.

Campbell, Jeffrey R., Charles L. Evans, Jonas D.M. Fisher, and Alejandro Justiniano, "Macroeconomic Effects of Federal Reserve Forward Guidance," Brookings Papers on Economic Activity, 2012, 44 (1 Spring), 1-80.

_ , Jonas D. M. Fisher, Alejandro Justiniano, and Leonardo Melosi, "Forward Guidance and Macroeconomic Outcomes Since the Financial Crisis," in "NBER Macroeconomics Annual 2016, Volume 31" NBER Chapters, National Bureau of Economic Research, Inc, February 2016.

Chan, Joshua C.C., Eric Eisenstat, and Gary Koop, "Large Bayesian VARMAs," Journal of Econometrics, 2016, 192 (2), 374-390.

Chevillon, Guillaume, "Direct Multi-Step Estimation and Forecasting," Journal of Economic Surveys, 2007, 21 (4), 746-785.

Chiuso, Alessandro, "Regularization and Bayesian Learning in Dynamical Systems: Past, Present and Future," CoRR, 2015, abs/1511.01543.

Christiano, Lawrence J., Martin Eichenbaum, and Charles L. Evans, "Monetary policy shocks: What have we learned and to what end?," in J. B. Taylor and M. Woodford, eds., Handbook of Macroeconomics, Vol. 1 of Handbook of Macroeconomics, Elsevier, 1999, chapter 2, pp. 65-148.

Cloyne, James and Patrick Hürtgen, "The Macroeconomic Effects of Monetary Policy: A New Measure for the United Kingdom," American Economic Journal: Macroeconomics, October 2016, 8 (4), 75-102.

Coibion, Olivier, "Are the Effects of Monetary Policy Shocks Big or Small?," American Economic Journal: Macroeconomics, April 2012, 4 (2), 1-32.

_ and Yuriy Gorodnichenko, "What Can Survey Forecasts Tell Us about Information Rigidities?," Journal of Political Economy, 2012, 120 (1), 116 - 159.

_ and _ , "Information Rigidity and the Expectations Formation Process: A Simple Framework and New Facts," American Economic Review, 2015, 105 (8), 2644-78.

Croushore, Dean and Simon van Norden, "Fiscal Forecasts at the FOMC: Evidence from the Greenbooks," Review of Economics and Statistics, 2017, forthcoming.

Dovern, Jonas, Ulrich Fritsche, and Jiri Slacalek, "Disagreement Among Forecasters in G7 Countries," The Review of Economics and Statistics, November 2012, 94 (4), 1081-1096. 
Ellingsen, Tore and Ulf Soderstrom, "Monetary Policy and Market Interest Rates," American Economic Review, December 2001, 91 (5), 1594-1607.

Friedman, Milton and David Meiselman, "The Relative Stability of Monetary Velocity and the Investment Multiplier in the United States, 1897-1958.," in "Commission on Money and Credit: Stabilization Policies," prentice-hall ed. Handbook of Macroeconomics, Englewood Cliffs, 1963, pp. 165-268.

Gaspar, Vitor, Frank Smets, and David Vestin, "Inflation Expectations, Adaptive Learning and Optimal Monetary Policy," in Benjamin M. Friedman and Michael Woodford, eds., Handbook of Monetary Economics, Vol. 3 of Handbook of Monetary Economics, Elsevier, 2010, chapter 19, pp. 1055-1095.

Gertler, Mark and Peter Karadi, "Monetary Policy Surprises, Credit Costs, and Economic Activity," American Economic Journal: Macroeconomics, 2015, 7 (1), 44-76.

Giannone, Domenico, Michele Lenza, and Giorgio E. Primiceri, "Prior Selection for Vector Autoregressions," The Review of Economics and Statistics, May 2015, 2 (97), $436-451$.

Gilchrist, Simon and Egon Zakrajšek, "Credit Spreads and Business Cycle Fluctuations," American Economic Review, 2012, 102 (4), 1692-1720.

_, David López-Salido, and Egon Zakrajšek, "Monetary Policy and Real Borrowing Costs at the Zero Lower Bound," American Economic Journal: Macroeconomics, January 2015, 7 (1), 77-109.

Gürkaynak, Refet S, "Using federal funds futures contracts for monetary policy analysis," Finance and Economics Discussion Series 2005-29, Board of Governors of the Federal Reserve System (U.S.) 2005.

_ , Brian Sack, and Eric Swanson, "Do Actions Speak Louder Than Words? The Response of Asset Prices to Monetary Policy Actions and Statements," International Journal of Central Banking, May 2005, 1 (1).

Hellwig, Martin F., "On the aggregation of information in competitive markets," Journal of Economic Theory, June 1980, 22 (3), 477-498.

Hubert, Paul and Becky Maule, "Policy and macro signals as inputs to inflation expectation formation," Bank of England working papers 581, Bank of England January 2016.

Jordà, Òscar, "Estimation and Inference of Impulse Responses by Local Projections," American Economic Review, March 2005, 95 (1), 161-182.

Kadiyala, K Rao and Sune Karlsson, "Numerical Methods for Estimation and Inference in Bayesian VAR-Models," Journal of Applied Econometrics, March-Apr 1997, 12 (2), 99-132.

Kilian, Lutz and Yun Jung Kim, "How Reliable Are Local Projection Estimators of Impulse Responses?," The Review of Economics and Statistics, November 2011, 93 (4), $1460-1466$.

Kuttner, Kenneth N., "Monetary policy surprises and interest rates: Evidence from the Fed funds futures market," Journal of Monetary Economics, June 2001, 47 (3), 523-544.

Leeper, Eric M., Christopher A. Sims, and Tao Zha, "What Does Monetary Policy Do?," Brookings Papers on Economic Activity, 1996, 27 (2), 1-78.

Litterman, Robert B, "Forecasting with Bayesian Vector Autoregressions-Five Years of Experience," Journal of Business \& Economic Statistics, January 1986, 4 (1), 25-38. 
Mackowiak, Bartosz and Mirko Wiederholt, "Optimal Sticky Prices under Rational Inattention," American Economic Review, June 2009, 99 (3), 769-803.

Mankiw, N. Gregory and Ricardo Reis, "Sticky Information Versus Sticky Prices: A Proposal To Replace The New Keynesian Phillips Curve," The Quarterly Journal of Economics, November 2002, 117 (4), 1295-1328.

_ and _, "Imperfect Information and Aggregate Supply," in Benjamin M. Friedman and Michael Woodford, eds., Handbook of Monetary Economics, Vol. 3 of Handbook of Monetary Economics, Elsevier, 2010, chapter 5, pp. 183-229.

_ , _ , and Justin Wolfers, "Disagreement about Inflation Expectations," in "NBER Macroeconomics Annual 2003, Volume 18" NBER Chapters, National Bureau of Economic Research, Inc, November 2004, pp. 209-270.

Marcellino, Massimiliano, James H. Stock, and Mark W. Watson, "A comparison of direct and iterated multistep AR methods for forecasting macroeconomic time series," Journal of Econometrics, 2006, 135 (1-2), 499-526.

McCracken, Michael W. and Serena Ng, "FRED-MD: A Monthly Database for Macroeconomic Research," Working Papers 2015-12, Federal Reserve Bank of St. Louis June 2015.

Melosi, Leonardo, "Signaling Effects of Monetary Policy," Review of Economic Studies, 2017, forthcoming.

Mertens, Karel and Morten O. Ravn, "The Dynamic Effects of Personal and Corporate Income Tax Changes in the United States," American Economic Review, 2013, 103 (4), $1212-47$.

Miranda-Agrippino, Silvia, "Unsurprising Shocks: Information, Premia, and the Monetary Transmission," Staff Working Paper 626, Bank of England 2016.

- and Hélène Rey, "World Asset Markets and the Global Financial Cycle," NBER Working Papers 21722, National Bureau of Economic Research, Inc November 2015.

Mishkin, Frederic S., "The Channels of Monetary Transmission: Lessons for Monetary Policy," NBER Working Papers 5464, National Bureau of Economic Research, Inc February 1996.

Müller, Ulrich K., "Risk of Bayesian Inference in Misspecified Models, and the Sandwich Covariance Matrix," Econometrica, 2013, 81 (5), 1805-1849.

Nakamura, Emi and Jón Steinsson, "High Frequency Identification of Monetary NonNeutrality," NBER Working Papers 19260, National Bureau of Economic Research, Inc July 2013.

Orphanides, Athanasios, "Monetary policy evaluation with noisy information," Journal of Monetary Economics, April 2003, 50 (3), 605-631.

Pesaran, M. Hashem, Andreas Pick, and Allan Timmermann, "Variable selection, estimation and inference for multi-period forecasting problems," Journal of Econometrics, September 2011, 164 (1), 173-187.

Plagborg-Moller, Mikkel, "Bayesian Inference on Structural Impulse Response Functions," Harvard mimeo, C.E.P.R. Discussion Papers October 2015.

Primiceri, Giorgio E., "Time Varying Structural Vector Autoregressions and Monetary Policy," Review of Economic Studies, 2005, 72 (3), 821-852.

Ramey, Valerie A., "Macroeconomic Shocks and Their Propagation," Working Paper 21978, National Bureau of Economic Research February 2016. 
Romer, Christina D. and David H. Romer, "Federal Reserve Information and the Behavior of Interest Rates," American Economic Review, 2000, 90 (3), 429-457.

_ and _, "A New Measure of Monetary Shocks: Derivation and Implications," American Economic Review, September 2004, 94 (4), 1055-1084.

Rudebusch, Glenn D, "Do Measures of Monetary Policy in a VAR Make Sense?," International Economic Review, November 1998, 39 (4), 907-31.

Schorfheide, Frank, "VAR forecasting under misspecification," Journal of Econometrics, September 2005, 128 (1), 99-136.

Sims, Christopher A., "Money, Income, and Causality," The American Economic Review, 1972, 62 (4), pp. 540-552.

_ , "Macroeconomics and Reality," Econometrica, January 1980, 48 (1), 1-48.

_ , "Interpreting the macroeconomic time series facts : The effects of monetary policy," European Economic Review, June 1992, 36 (5), 975-1000.

_, "Comment on Glenn Rudebusch's "Do Measures of Monetary Policy in a VAR Make Sense?"," International Economic Review, November 1998, 39 (4), 933-41.

_ , "Implications of rational inattention," Journal of Monetary Economics, April 2003, 50 (3), 665-690.

_ , "Rational Inattention and Monetary Economics," in Benjamin M. Friedman and Michael Woodford, eds., Handbook of Monetary Economics, Vol. 3 of Handbook of Monetary Economics, Elsevier, 2010, chapter 4, pp. 155-181.

Smets, Frank and Rafael Wouters, "Shocks and Frictions in US Business Cycles: A Bayesian DSGE Approach," American Economic Review, June 2007, 97 (3), 586-606.

Stock, James H. and Mark W. Watson, "Disentangling the Channels of the 2007-09 Recession," Brookings Papers on Economic Activity, 2012, 44 (1 (Spring), 81-156.

Uhlig, Harald, "What are the effects of monetary policy on output? Results from an agnostic identification procedure," Journal of Monetary Economics, March 2005, 52 (2), 381-419.

Woodford, M., Interest and Prices: Foundations of a Theory of Monetary Policy, Princeton University Press, 2011.

Woodford, Michael, "Imperfect Common Knowledge and the Effects of Monetary Policy," NBER Working Papers 8673, National Bureau of Economic Research, Inc December 2001. 


\section{A Derivations - For Online Publication}

\section{A.1 Aggregate Expectation Revisions}

Recall from Section 1 that at $\underline{t}$ both agents and the central bank receive signals about the economy, and as a result of that, update their expectations. Specifically, at opening time $\underline{t}$ each agent $i$ observes a private noisy signal of the state of the economy $x_{t}$

$$
s_{i, \underline{\underline{t}}}=x_{t}+\nu_{i, \underline{t}}, \quad \nu_{i, \underline{t}} \sim \mathcal{N}\left(0, \sigma_{n, \nu}\right) .
$$

We assume the $k$-dimensional vector of macroeconomic fundamentals to evolve following an $\operatorname{AR}(1)$

$$
x_{t}=\rho x_{t-1}+\xi_{t} \quad \xi_{t} \sim \mathcal{N}\left(0, \Sigma_{\xi}\right),
$$

where $\xi_{t}$ is the vector of structural shocks.

Given the signals, agents update their expectations using

$$
\begin{array}{lrl}
F_{i, \underline{t}} x_{t} & =K_{1} s_{i, \underline{t}}+\left(1-K_{1}\right) F_{i, \overline{t-1}} x_{t}, \\
F_{i, \underline{t}} x_{t+h}=\rho^{h} F_{i, \underline{t}} x_{t} & \forall h>0,
\end{array}
$$

where $K_{1}$ is the Kalman gain which represents the relative weight placed on new information relative to previous forecasts. When the signal is perfectly revealing $K_{1}=1$, while in the presence of noise $K_{1}<1$. Thus $\left(1-K_{1}\right)$ is the degree of information rigidity faced by the agents. The central bank observes

$$
s_{c b, \underline{t}}=x_{t}+\nu_{c b, \underline{t}}, \quad \quad \nu_{c b, \underline{t}} \sim \mathcal{N}\left(0, \sigma_{c b, \nu}\right) .
$$

We can assume without loss of generality that the signal observed by the central bank is more precise than the one observed by agents: $\sigma_{c b, \nu}<\sigma_{n, \nu}$. Given the signal, the central bank updates its expectations via the Kalman filter

$$
\begin{array}{lrl}
F_{c b, \underline{t}} x_{t} & =K_{c b} s_{c b, \underline{t}}+\left(1-K_{c b}\right) F_{c b, \overline{t-1}} x_{t}, \\
F_{c b, \underline{t}} x_{t+h} & =\rho^{h} F_{c b, \underline{t}} x_{t} & \forall h>0,
\end{array}
$$


where $K_{c b}$ is the central bank's Kalman gain.

At $\bar{t}$ agents observe the policy rate (i.e. a common signal from the central bank) and update their forecasts using

$$
\begin{array}{lrl}
F_{i, \bar{t}} x_{t} & =K_{2} \tilde{s}_{c b, \bar{t}}+\left(1-K_{2}\right) F_{i, \underline{t}} x_{t}, \\
F_{i, \bar{t}} x_{t+h} & =\rho^{h} F_{i, \bar{t}} x_{t} & \forall h>0,
\end{array}
$$

where $\tilde{s}_{c b, \bar{t}}$ indicates the generic public signal that agents extract from the interest rate decision, and $K_{2}$ is the Kalman gain given the noise in the public signal $\tilde{\nu}_{c b, \underline{t}}$.

Combining Eq. (A.8) with Eq. (A.3), and using Eq. (A.2) and Eq. (A.9) we find

$$
\begin{aligned}
F_{i, \bar{t}} x_{t}-F_{i, \underline{t}} x_{t} & =K_{2}\left[\tilde{s}_{c b, \bar{t}}-F_{i, \underline{t}} x_{t}\right] \\
& =K_{2}\left(x_{t}+\tilde{\nu}_{c b, \bar{t}}\right)-K_{2}\left[K_{1}\left(x_{t}+\nu_{i, \bar{t}}\right)+\left(1-K_{1}\right) F_{i, \overline{t-1}} x_{t}\right] \\
& =K_{2}\left(1-K_{1}\right) x_{t}+K_{2} \tilde{\nu}_{c b, \bar{t}}-K_{2} K_{1} \nu_{i, \bar{t}}-K_{2}\left(1-K_{1}\right) F_{i, \overline{t-1}} x_{t} \\
& =K_{2}\left(1-K_{1}\right) \rho\left[x_{t-1}-F_{i, \overline{t-1}} x_{t-1}\right]+K_{2}\left[\left(1-K_{1}\right) \xi_{t}+\tilde{\nu}_{c b, \bar{t}}-K_{1} \nu_{i, \bar{t}}\right] .
\end{aligned}
$$

To find an expression for the forecast error $\left(x_{t-1}-F_{i, \overline{t-1}} x_{t-1}\right)$ in Eq. (A.10), first note that Eq. (A.8) implies

$$
x_{t}-F_{i, \bar{t}} x_{t}=K_{2}^{-1}\left(1-K_{2}\right)\left(F_{i, \bar{t}} x_{t}-F_{i, \underline{t}} x_{t}\right)-\tilde{\nu}_{c b, \bar{t}} .
$$

Then Eq. (A.11) one period earlier can be written as

$$
\begin{aligned}
x_{t-1}-F_{i, \overline{t-1}} x_{t-1} & =K_{2}^{-1}\left(1-K_{2}\right)\left[F_{i, \overline{t-1}} x_{t-1}-F_{i, \underline{t-1}} x_{t-1}\right]-\tilde{\nu}_{c b, \overline{t-1}} \\
& =K_{2}^{-1}\left(1-K_{2}\right) \rho^{-1}\left[F_{i, \overline{t-1}} x_{t}-F_{i, \underline{t-1}} x_{t}\right]-\tilde{\nu}_{c b, \overline{t-1}} .
\end{aligned}
$$

Substituting Eq. (A.12) into Eq. (A.10) yields

$$
\begin{aligned}
F_{i, \bar{t}} x_{t}-F_{i, \underline{t}} x_{t}= & \left(1-K_{2}\right)\left(1-K_{1}\right)\left[F_{i, \overline{t-1}} x_{t}-F_{i, \underline{t-1}} x_{t}\right] \\
& +K_{2}\left[\left(1-K_{1}\right) \xi_{t}+\left(\tilde{\nu}_{c b, \bar{t}}-\left(1-K_{1}\right) \rho \tilde{\nu}_{c b, \overline{t-1}}\right)-K_{1} \nu_{i, \bar{t}}\right] .
\end{aligned}
$$

The characteristics of the common noise $\tilde{\nu}_{c b, \bar{t}}$ are derived from the Taylor rule in Eq. (4), and 
the signal extraction problem of the central bank in Eq. (A.6). Specifically:

$$
\begin{aligned}
i_{t} & =\phi_{0}+\phi_{x}^{\prime} F_{c b, \underline{t}} x_{t}+u_{t} \\
& =\phi_{0}+\phi_{x}^{\prime}\left[K_{c b} s_{c b, \underline{t}}+\left(1-K_{c b}\right) F_{c b, \overline{t-1}} x_{t}\right]+u_{t} \\
& =\phi_{0}+\phi_{x}^{\prime}\left[K_{c b} s_{c b, \underline{t}}+\left(1-K_{c b}\right) \rho F_{c b, \overline{t-1}} x_{t-1}\right]+u_{t} \\
& =\phi_{0}+K_{c b} \phi_{x}^{\prime} s_{c b, \underline{t}}+\left(1-K_{c b}\right) \rho\left(i_{t-1}-\phi_{0}-u_{t-1}\right)+u_{t} \\
& =\left[1-\left(1-K_{c b}\right) \rho\right] \phi_{0}+\left(1-K_{c b}\right) \rho i_{t-1}+K_{c b} \phi_{x}^{\prime} s_{c b, \underline{t}}-\left(1-K_{c b}\right) \rho u_{t-1}+u_{t},
\end{aligned}
$$

with $F_{c b, \overline{t-1}} x_{t-1}=F_{c b, t-1} x_{t-1}$. Thus, conditional on $i_{t-1}$, at announcement agents observe the common signal

$$
\tilde{s}_{c b, \bar{t}}=x_{t}+\nu_{c b, \underline{t}}+\left(K_{c b} \phi_{x}^{\prime}\right)^{-1}\left[u_{t}-\left(1-K_{c b}\right) \rho u_{t-1}\right],
$$

where

$$
\tilde{\nu}_{c b, \underline{t}}=\nu_{c b, \underline{t}}+\left(K_{c b} \phi_{x}^{\prime}\right)^{-1}\left[u_{t}-\left(1-K_{c b}\right) \rho u_{t-1}\right] .
$$

Plugging Eq. (A.16) into Eq. (A.13) yields

$$
\begin{aligned}
F_{i, \bar{t}} x_{t}-F_{i, \underline{t}} x_{t}= & \left(1-K_{2}\right)\left(1-K_{1}\right)\left[F_{i, \overline{t-1}} x_{t}-F_{i, \underline{t-1}} x_{t}\right] \\
& +K_{2}\left(1-K_{1}\right) \xi_{t}+K_{2}\left[\left(\nu_{c b, \bar{t}}-\left(1-K_{1}\right) \rho \nu_{c b, \overline{t-1}}\right)-K_{1} \nu_{i, \bar{t}}\right] \\
& +K_{2}\left(K_{c b} \phi_{x}^{\prime}\right)^{-1}\left[u_{t}-\left(K_{1}-K_{c b}\right) \rho u_{t-1}-\rho\left(1-K_{1}\right)\left(1-K_{c b}\right) \rho^{2} u_{t-2}\right] .
\end{aligned}
$$

Eq. (7) follows by taking the average of Eq. (A.17) over the agents $i$.

\section{A.2 Bias in OLS Regression}

Recall Eq. (7):

$$
\begin{aligned}
F_{\bar{t}} x_{t}-F_{\underline{t}} x_{t}= & \left(1-K_{2}\right)\left(1-K_{1}\right)\left[F_{\overline{t-1}} x_{t}-F_{\underline{t-1}} x_{t}\right] \\
& +K_{2}\left(1-K_{1}\right) \xi_{t}+K_{2}\left[\nu_{c b, \underline{t}}-\left(1-K_{1}\right) \rho \nu_{c b, \underline{t-1}}\right] \\
& +K_{2}\left(K_{c b} \phi_{x}^{\prime}\right)^{-1}\left[u_{t}-\rho\left(K_{1}-K_{c b}\right) u_{t-1}+\left(1-K_{1}\right)\left(1-K_{c b}\right) \rho^{2} u_{t-2}\right] .
\end{aligned}
$$


For simplicity, let us consider the vector $x_{t}$ to be univariate. Suppose one runs a regression of the form (e.g. top panel of Table 1)

$$
F_{\bar{t}} x_{t}-F_{\underline{t}} x_{t}=\beta\left[F_{\overline{t-1}} x_{t}-F_{\underline{t-1}} x_{t}\right]+\text { error }_{t} .
$$

Then, using $\mathbb{E}\left[F_{\overline{t-1}} x_{t} \xi_{t}\right]=0$ and $\mathbb{E}\left[F_{\overline{t-1}} x_{t} u_{t}\right]=0$ we get

$$
\begin{aligned}
\hat{\beta}^{O L S}= & \frac{\mathbb{E}\left[\left(F_{\bar{t}} x_{t}-F_{\underline{t}} x_{t}\right)\left(F_{\overline{t-1}} x_{t}-F_{\underline{t-1}} x_{t}\right)\right]}{\mathbb{E}\left[\left(F_{\overline{t-1}} x_{t}-F_{\underline{t-1}} x_{t}\right)^{2}\right]} \\
= & \left(1-K_{2}\right)\left(1-K_{1}\right)-K_{2}\left(1-K_{1}\right) \rho \frac{\mathbb{E}\left[\left(F_{\overline{t-1}} x_{t}-F_{t-1} x_{t}\right) \nu_{c b, t-1}\right]}{\mathbb{E}\left[\left(F_{\overline{t-1}} x_{t}-F_{\underline{t-1}} x_{t}\right)^{2}\right]} \\
& -K_{2}\left(K_{c b} \phi_{x}^{\prime}\right)^{-1}\left(K_{1}-K_{c b}\right) \rho \frac{\mathbb{E}\left[\left(F_{\overline{t-1}} x_{t}-F_{t-1} x_{t}\right) u_{t-1}\right]}{\mathbb{E}\left[\left(F_{\overline{t-1}} x_{t}-F_{t-1} x_{t}\right)^{2}\right]}+\mathcal{O}\left(\rho^{3}\right) \\
= & \left(1-K_{2}\right)\left(1-K_{1}\right)-K_{2}\left(1-K_{1}\right) \rho \frac{\mathbb{E}\left[\rho F_{\overline{t-1}} x_{t-1} \nu_{c b, t-1}\right]}{\mathbb{E}\left[\left(F_{\overline{t-1}} x_{t}-F_{\underline{t-1}} x_{t}\right)^{2}\right]} \\
& -K_{2}\left(K_{c b} \phi_{x}^{\prime}\right)^{-1}\left(K_{1}-K_{c b}\right) \rho \frac{\mathbb{E}\left[\rho F_{\overline{t-1}} x_{t-1} u_{t-1}\right]}{\mathbb{E}\left[\left(F_{\overline{t-1}} x_{t}-F_{t-1} x_{t}\right)^{2}\right]}+\mathcal{O}\left(\rho^{3}\right) \\
= & \left(1-K_{2}\right)\left(1-K_{1}\right)-K_{2}\left(1-K_{1}\right) \rho^{2} \frac{\overline{\Sigma_{c b}}\left[\left(F_{\overline{t-1}} x_{t}-F_{t-1} x_{t}\right)^{2}\right]}{\mathbb{E}} \\
& -K_{2}\left(K_{c b} \phi_{x}^{\prime}\right)^{-1}\left(K_{1}-K_{c b}\right) \rho^{2} \frac{\Sigma_{u}}{\mathbb{E}\left[\left(F_{\overline{t-1}} x_{t}-F_{\underline{t-1}} x_{t}\right)^{2}\right]}+\mathcal{O}\left(\rho^{3}\right) .
\end{aligned}
$$

The size of the last term in Eq. (A.18) depends on the relative magnitude of $K_{1}$ and $K_{c b}$. The Kalman gain of the agents and the central bank are likely to be similar, due to similar degree of precision of the signals. Hence, the third term is negligible, resulting in an overall negative bias. 


\section{B Priors for BLP - For Online Publication}

\section{B.1 Informative Priors for LP}

Horizon- $h$ IRFs estimated with the Local Projection method (LP, Jordà, 2005), are the coefficients in $B_{1}^{(h)}$ estimated from the linear regression

$$
\begin{aligned}
& y_{t+h}=C^{(h)}+B_{1}^{(h)} y_{t}+\ldots+B_{\tilde{p}}^{(h)} y_{t-(\tilde{p}+1)}+\varepsilon_{t+h}^{(h)}, \\
& \varepsilon_{t+h}^{(h)} \sim \mathcal{N}\left(0, \Sigma_{\varepsilon}^{(h)}\right) \quad \forall h=1, \ldots, H,
\end{aligned}
$$

where $\tilde{p}$ may depend on $h$. The residuals $\varepsilon_{t+h}^{(h)}$, being a combination of one-step-ahead forecast errors, are serially correlated and heteroskedastic.

For the coefficients of Eq. (B.1) at each horizon $h$ we specify standard conjugate Normalinverse Wishart priors

$$
\begin{aligned}
& \Sigma_{\varepsilon}^{(h)} \mid \gamma \sim \mathcal{I} \mathcal{W}\left(\Psi_{0}^{(h)}, d_{0}^{(h)}\right), \\
& \beta^{(h)} \mid \Sigma_{\varepsilon}^{(h)}, \gamma \sim \mathcal{N}\left(\beta_{0}^{(h)}, \Sigma_{\varepsilon}^{(h)} \otimes \Omega_{0}^{(h)}(\gamma)\right),
\end{aligned}
$$

where $\beta^{(h)} \equiv \operatorname{vec}\left(b^{(h)}\right)=\operatorname{vec}\left(\left[C^{(h)}, B_{1}^{(h)}, \ldots, B_{\tilde{p}}^{(h)}\right]^{\prime}\right)$. We use $\gamma$ to denote the generic vector collecting all the priors' hyperparameters.

As in Kadiyala and Karlsson (1997), we set $d_{0}^{(h)}=n+2$, to guarantee the existence of the prior mean for $\Sigma_{\varepsilon}^{(h)}$, equal to $\Psi_{0}^{(h)} /\left(d_{0}^{(h)}-n-1\right)$. As is standard, we use sample information to fix some of the entries in Eq. (B.2). We set $\Psi_{0}^{(h)}$ equal to

$$
\Psi_{0}^{(h)}=\operatorname{diag}\left(\left[\left(\sigma_{1}^{(h)}\right)^{2}, \ldots,\left(\sigma_{n}^{(h)}\right)^{2}\right]\right)
$$

where $\left(\sigma_{i}^{(h)}\right)^{2}$ are HAC-corrected variances of univariate local projection residuals. Similarly, we set $\Omega_{0}^{(h)}$ to be

$$
\underset{(n \tilde{p}+1 \times n \tilde{p}+1)}{\Omega_{0}^{(h)}(\gamma)}=\left(\begin{array}{cc}
\epsilon^{-1} & 0 \\
0 & \mathbb{I}_{\tilde{p}} \otimes\left(\lambda^{(h)}\right)^{2} \operatorname{diag}\left(\left[\left(\sigma_{1}^{(h)}\right)^{2}, \ldots,\left(\sigma_{n}^{(h)}\right)^{2}\right]\right)^{-1}
\end{array}\right),
$$

where $\epsilon$ is a very small number (diffuse prior on the intercepts). The hyperparameter $\lambda^{(h)}$ 
controls the overall tightness of the priors at each horizon $h$, i.e. $\gamma \equiv \lambda^{(h)}$.

This specification implies the following moments for the IRF coefficients

$$
\begin{aligned}
\mathbb{E}\left[B_{i j}^{(h)} \mid \Sigma_{\varepsilon}^{(h)}\right] & =B_{0, i j}^{(h)}, \\
\operatorname{Var}\left[B_{i j}^{(h)} \mid \Sigma_{\varepsilon}^{(h)}\right] & =\left(\lambda^{(h)}\right)^{2} \frac{\left(\sigma_{i}^{(h)}\right)^{2}}{\left(\sigma_{j}^{(h)}\right)^{2}},
\end{aligned}
$$

where $B_{i j}^{(h)}$ is the response of variable $i$ to shock $j$ at horizon $h$, and $B_{0}^{(h)}$ is such that $\beta_{0}^{(h)}=$ $\operatorname{vec}\left(B_{0}^{(h)}\right)$.

We set $\beta_{0}^{(h)}$ to be equal to the horizon- $h \operatorname{IRFs}$ resulting from a $\operatorname{VAR}(p)$ estimated on a pre-sample $T_{0}$ that is then discarded:

$$
\beta_{0}^{(h)}=\operatorname{vec}\left(B_{T_{0}}^{h}\right),
$$

where $B_{T_{0}}^{h}$ is the $h$-th power of the VAR coefficients estimated over $T_{0}$ using standard priors (Litterman, 1986).

Having not explicitly modelled the autocorrelation of $\varepsilon_{t+h}^{(h)}$ has two important implications. First, the priors are conjugate. Second, the Kronecker structure of the standard macroeconomic priors is preserved. This makes the estimation both analytically and computationally tractable. Conditional on the data, the posterior distribution takes the following form

$$
\begin{aligned}
& \Sigma_{\varepsilon}^{(h)} \mid \gamma^{(h)}, \mathrm{y} \sim \mathcal{I} \mathcal{W}\left(\Psi^{(h)}, d\right) \\
& \beta^{(h)} \mid \Sigma_{\varepsilon}^{(h)}, \gamma^{(h)}, \mathrm{y} \sim \mathcal{N}\left(\tilde{\beta}^{(h)}, \Sigma_{\varepsilon}^{(h)} \otimes \Omega^{(h)}\right),
\end{aligned}
$$

where $d=d_{0}^{(h)}+T$, and $T$ is the sample size.

Because $\varepsilon_{t+h}^{(h)}$ are a combination of past forecast errors, Eq. (B.6) is misspecified. The shape of the true likelihood is asymptotically Gaussian and centred at the Maximum Likelihood Estimator (MLE), but has a different (larger) variance than the one in Eq. (B.6). We follow Müller (2013) and, in line with the classical practice, construct posterior coverage bands for the BLP responses using an artificial Gaussian 'sandwich' posterior that is centred at the MLE 
Figure B.1: BLP RESPONSES: VAR vs RW PRIOR
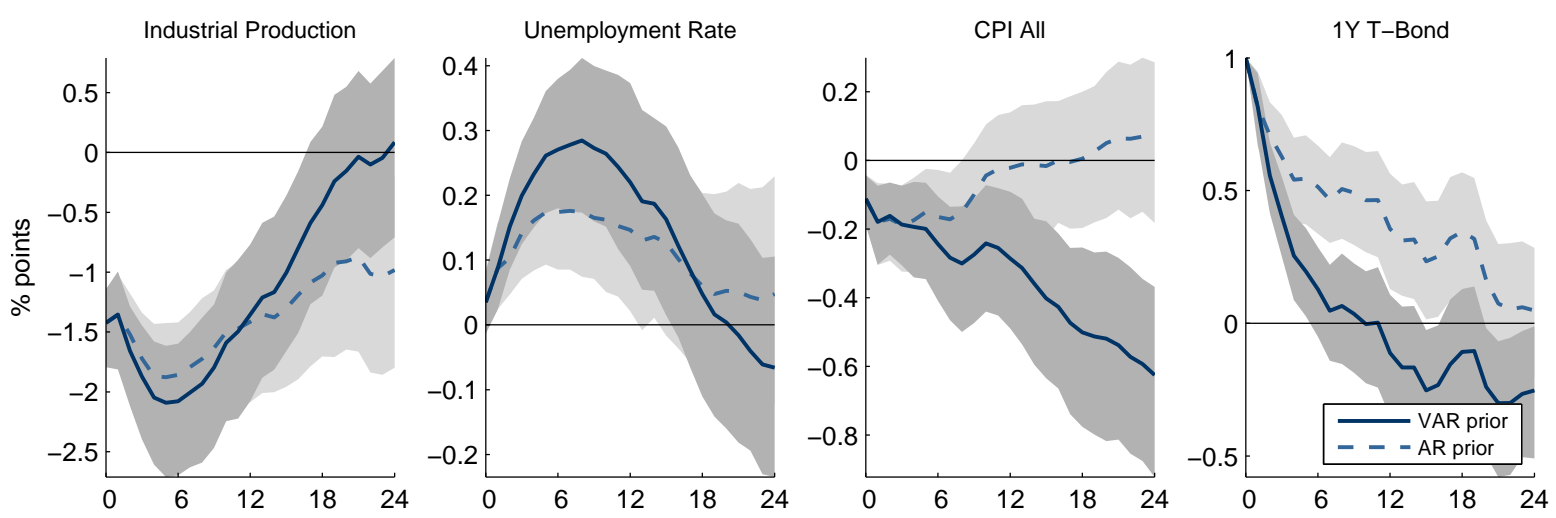

Note: BLP(12) with $R W$ prior (teal, dashed), and BLP(12) with VAR(12) prior (blue, solid). 1979:2014. Pre-Sample 1969:1979.

but with a HAC-corrected covariance matrix. Specifically, we replace Eq. (B.6) with

$$
\begin{aligned}
& \Sigma_{\varepsilon, \mathrm{HAC}}^{(h)} \mid \gamma^{(h)}, \mathrm{y} \sim \mathcal{I} \mathcal{W}\left(\Psi_{\mathrm{HAC}}^{(h)}, d\right), \\
& \beta^{(h)} \mid \Sigma_{\varepsilon, \mathrm{HAC}}^{(h)}, \gamma^{(h)}, \mathrm{y} \sim \mathcal{N}\left(\tilde{\beta}^{(h)}, \Sigma_{\varepsilon, \mathrm{HAC}}^{(h)} \otimes \Omega^{(h)}\right) .
\end{aligned}
$$

We explore the role of our choice for the prior mean in Figure B.1. Here, the dashed lines are BLP responses obtained by replacing at each horizon $h$ the $\operatorname{VAR}(12)$ prior with a simpler univariate autoregressive (AR) prior in the spirit of Litterman (1986). BLP responses with our preferred VAR prior are the solid blue lines, and are the same as in Figure 3. We note that BLP responses are robust to the choice of the prior for the LP coefficients. However, the AR prior potentially discards important information in the off-diagonal entries of the matrices of autoregressive coefficients that are relevant for the dynamic responses of correlated variables to the shock.

\section{B.2 Optimal Prior Tightness}

The hyperparameter $\lambda^{(h)}$ controls the informativeness of the priors. Following Giannone, Lenza and Primiceri (2015), we treat $\lambda^{(h)}$ as an additional model parameter for which we specify a hyperprior $p\left(\lambda^{(h)}\right)$, and estimate it at each $h$ in the spirit of hierarchical modelling. Specifically, 
we maximise

$$
p\left(\lambda^{(h)} \mid \mathrm{y}^{(h)}\right)=p\left(\mathrm{y}^{(h)} \mid \lambda^{(h)}\right) \cdot p\left(\lambda^{(h)}\right),
$$

where $p\left(\mathrm{y}^{(h)} \mid \lambda^{(h)}\right)$ is the marginal density of the data as a function of the hyperparameters

$$
p\left(\mathrm{y}^{(h)} \mid \lambda^{(h)}\right)=\int p\left(\mathrm{y}^{(h)} \mid \lambda^{(h)}, \theta\right) p\left(\theta \mid \lambda^{(h)}\right) d \theta \forall h
$$

and $p\left(\theta \mid \lambda^{(h)}\right)$ is the prior distribution of the remaining model's parameters conditional on $\lambda^{(h)} \cdot \mathrm{y}^{(h)}=\operatorname{vec}\left(\mathrm{Y}^{(h)}\right)$ where $Y^{(h)} \equiv\left(y_{p+1+h}, \ldots, y_{T}\right)^{\prime}$. Under a flat hyperprior, the procedure corresponds to maximising the marginal data density (or marginal likelihood, ML).

Extending the argument in Giannone et al. (2015) we write the ML as

$$
p\left(\mathrm{y}^{(h)} \mid \lambda^{(h)}\right) \propto \underbrace{\left|\left(V_{\varepsilon^{(h)}}^{\text {posterior }}\right)^{-1} V_{\varepsilon^{(h)}}^{\mathrm{prior}}\right| \frac{T-(\tilde{p}+h)+d}{2}}_{\text {Fit }} \underbrace{\prod_{t=\tilde{p}+1}^{T-h}\left|V_{t+h \mid t}\right|^{-\frac{1}{2}}}_{\text {Penalty }} \forall h
$$

where $V_{\varepsilon^{(h)}}^{\text {posterior }}$ and $V_{\varepsilon^{(h)}}^{\text {prior }}$ are the posterior and prior mean of $\Sigma_{\varepsilon}^{(h)}$, and $V_{t+h \mid t}=\mathbb{E}_{\Sigma_{\varepsilon}^{(h)}}\left[\operatorname{Var}\left(y_{t+h} \mid \mathrm{y}^{t}, \Sigma_{\varepsilon}^{(h)}\right)\right]$ is the variance (conditional on $\Sigma_{\varepsilon}^{(h)}$ ) of the $h$-step-ahead forecast of $y_{t}$, averaged across all possible a priori realisations of $\Sigma_{\varepsilon}^{(h)}$. The first term in Eq. (B.10) relates to the model's in-sample fit, and it increases when $V_{\varepsilon^{(h)}}^{\text {posterior }}$ falls relative to $V_{\varepsilon^{(h)}}^{\text {prior }}$. The second term is related to the model's (pseudo) out-of-sample forecasting performance, and it increases in the risk of overfitting (i.e. with either large uncertainty around parameters' estimates, or large a-priori residual variance). Hence, the ML criterion favours hyperparameters values that generate both smaller forecast errors, and low forecast error variance, therefore balancing the trade-off between model fit and variance.

We choose $p\left(\lambda^{(h)}\right), p=1, \ldots, H$ from a family of Gamma distributions. We specify the Gamma hyperprior to be more diffuse the larger $h$, consistent with the idea that misspecifications compound as the horizon grows. This is accomplished by choosing the scale and shape parameters of the Gamma distribution such that the mode of the distribution is fixed at 0.4, and the standard deviation is a Logistic function of $h$ that reaches its maximum at horizons larger than $h=36$. The Logistic function is specified as follows

$$
\operatorname{sd}\left(\lambda^{(h)}\right)=0.1+0.4 /[1+\exp (-0.3(h-12))]
$$


and plotted in Figure B.2a. Figure B.2b illustrates the evolution of the hyperprior for $\lambda^{(h)}$ as a function of the horizon.

\section{Figure B.2: HyPERPRIOR FOR BLP-IRF COEFFICIENTS}

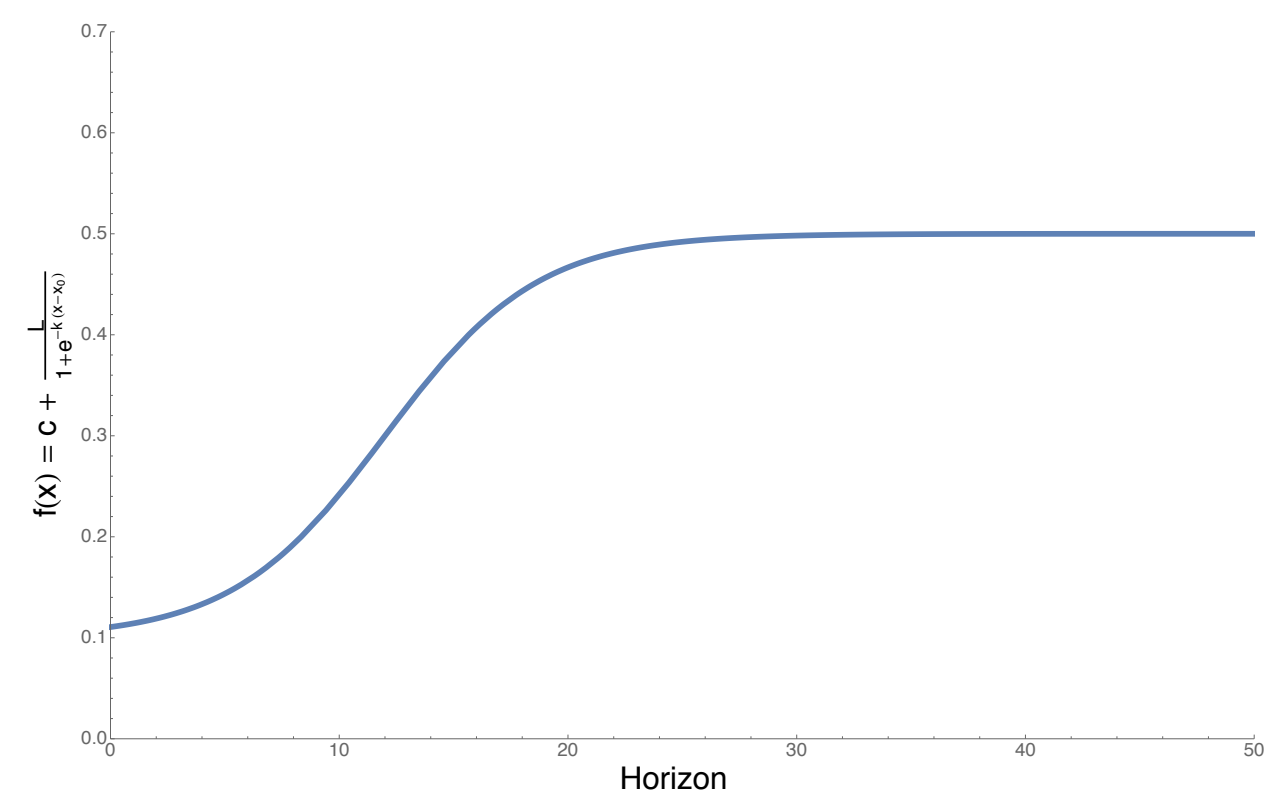

(A) Standard deviation of the hyperprior as a Logistic function of $h$.

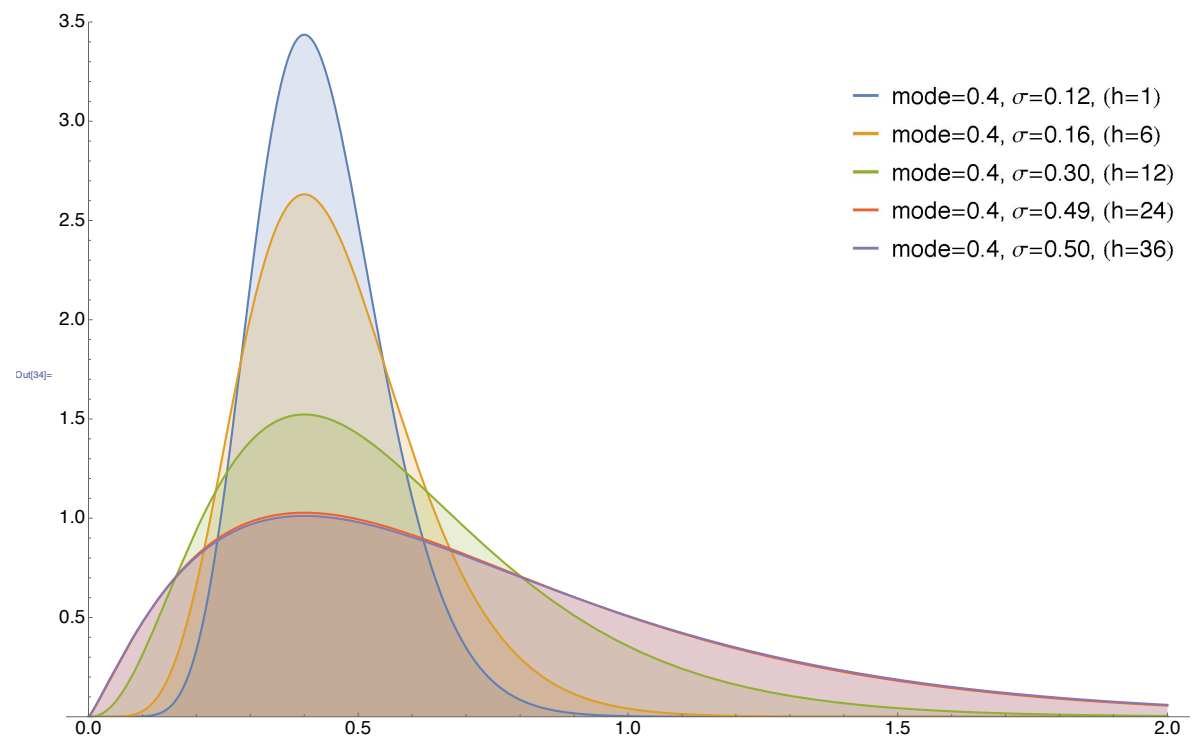

(в) Hyperprior Gamma distributions for a selection of horizons. 


\section{Other Charts and Tables - For Online Publication}

Table C.1: Test For Information Frictions - 1994:2009

\begin{tabular}{|c|c|c|c|c|c|c|}
\hline \multirow[b]{2}{*}{ lag 1} & \multicolumn{2}{|c|}{$F F 4_{t}$} & \multicolumn{2}{|c|}{$F F 4_{t}^{G K}$} & \multicolumn{2}{|c|}{$M P N_{t}$} \\
\hline & $\begin{array}{l}0.009 \\
{[0.13]}\end{array}$ & & $\begin{array}{l}0.419 \\
{[5.67]^{* * *}}\end{array}$ & & $\begin{array}{l}-0.059 \\
{[-0.67]}\end{array}$ & \\
\hline $\operatorname{lag} 2$ & $\begin{array}{l}-0.109 \\
{[-1.48]}\end{array}$ & & $\begin{array}{l}-0.290 \\
{[-3.62]^{* * *}}\end{array}$ & & $\begin{array}{l}0.206 \\
{[2.61]^{* *}}\end{array}$ & \\
\hline lag 3 & $\begin{array}{l}0.040 \\
{[0.55]}\end{array}$ & & $\begin{array}{l}0.092 \\
{[1.14]}\end{array}$ & & $\begin{array}{l}0.560 \\
{[7.08]^{* * *}}\end{array}$ & \\
\hline $\operatorname{lag} 4$ & $\begin{array}{l}0.085 \\
{[1.16]}\end{array}$ & & $\begin{array}{l}0.122 \\
{[1.47]}\end{array}$ & & $\begin{array}{l}0.076 \\
{[0.83]}\end{array}$ & \\
\hline$f_{1, t-1}$ & & $\begin{array}{l}-0.009 \\
{[-1.35]}\end{array}$ & & $\begin{array}{l}-0.010 \\
{[-2.65]^{* * *}}\end{array}$ & & $\begin{array}{l}-0.146 \\
{[-4.58]^{* * *}}\end{array}$ \\
\hline$f_{2, t-1}$ & & $\begin{array}{l}0.002 \\
{[0.75]}\end{array}$ & & $\begin{array}{l}0.004 \\
{[1.71]^{*}}\end{array}$ & & $\begin{array}{l}-0.011 \\
{[-0.76]}\end{array}$ \\
\hline$f_{3, t-1}$ & & $\begin{array}{l}-0.003 \\
{[-0.77]}\end{array}$ & & $\begin{array}{l}-0.005 \\
{[-1.38]}\end{array}$ & & $\begin{array}{l}-0.041 \\
{[-1.87]^{*}}\end{array}$ \\
\hline$f_{4, t-1}$ & & $\begin{array}{l}0.010 \\
{[1.30]}\end{array}$ & & $\begin{array}{l}0.007 \\
{[1.67]^{*}}\end{array}$ & & $\begin{array}{l}0.079 \\
{[2.53]^{* *}}\end{array}$ \\
\hline$f_{5, t-1}$ & & $\begin{array}{l}0.005 \\
{[0.68]}\end{array}$ & & $\begin{array}{l}0.000 \\
{[-0.04]}\end{array}$ & & $\begin{array}{l}0.028 \\
{[0.83]}\end{array}$ \\
\hline$f_{6, t-1}$ & & $\begin{array}{l}-0.014 \\
{[-2.44]^{* *}}\end{array}$ & & $\begin{array}{l}-0.007 \\
{[-2.75]^{* * *}}\end{array}$ & & $\begin{array}{l}0.018 \\
{[0.91]}\end{array}$ \\
\hline$f_{7, t-1}$ & & $\begin{array}{l}-0.014 \\
{[-1.89]^{*}}\end{array}$ & & $\begin{array}{l}-0.011 \\
{[-2.38]^{* *}}\end{array}$ & & $\begin{array}{l}-0.061 \\
{[-2.44]^{* *}}\end{array}$ \\
\hline$f_{8, t-1}$ & & $\begin{array}{l}0.000 \\
{[-0.10]}\end{array}$ & & $\begin{array}{l}-0.001 \\
{[-0.23]}\end{array}$ & & $\begin{array}{l}-0.044 \\
{[-1.88]^{*}}\end{array}$ \\
\hline$f_{9, t-1}$ & & $\begin{array}{l}-0.002 \\
{[-0.43]}\end{array}$ & & $\begin{array}{l}-0.001 \\
{[-0.36]}\end{array}$ & & $\begin{array}{l}-0.045 \\
{[-1.79]^{*}}\end{array}$ \\
\hline$f_{10, t-1}$ & & $\begin{array}{l}0.004 \\
{[0.75]}\end{array}$ & & $\begin{array}{l}0.001 \\
{[0.22]}\end{array}$ & & $\begin{array}{l}-0.039 \\
{[-2.48]^{* *}}\end{array}$ \\
\hline$r^{2}$ & 0.002 & 0.132 & 0.168 & 0.210 & 0.282 & 0.269 \\
\hline$F$ & 1.083 & 1.957 & 10.205 & 3.339 & 16.531 & 3.532 \\
\hline$p$ & 0.366 & 0.035 & 0.000 & 0.000 & 0.000 & 0.000 \\
\hline$N$ & 183 & 189 & 183 & 189 & 159 & 165 \\
\hline
\end{tabular}

Note: Regressions are estimated over the sample 1994:2009. From left to right, the monthly surprise in the fourth federal funds future $\left(F F 4_{t}\right)$, the instrument in Gertler and Karadi (2015) $\left(F F 4_{t}^{G K}\right)$, the narrative series of Romer and Romer $(2004)\left(M P N_{t}\right)$. t-statistics are reported in square brackets, * $p<0.1,{ }^{* *} p<0.05,{ }^{* * *} p<0.01$. Constant included. Regressions on factors include a lag of the dependent variable. Robust SE. 
TABle C.2: Variables Used

\begin{tabular}{|c|c|c|c|c|c|c|c|}
\hline \multirow[b]{2}{*}{ Code } & \multirow[b]{2}{*}{ Variable Name } & \multirow[b]{2}{*}{ Source } & \multirow[b]{2}{*}{$\log$} & \multicolumn{4}{|c|}{ MODEL } \\
\hline & & & & (1) & $(2)$ & $(3)$ & (4) \\
\hline INDPRO & Industrial Production & FRED & - & $\bullet$ & $\bullet$ & $\bullet$ & $\bullet$ \\
\hline CAPUTLB00004S & Capacity Utilization & FRED & $\bullet$ & $\bullet$ & $\bullet$ & $\bullet$ & $\bullet$ \\
\hline UNRATE & Unemployment Rate & FRED & & $\bullet$ & $\bullet$ & $\bullet$ & $\bullet$ \\
\hline AWHMAN & Average Weekly Hours Mfg & FRED & - & & - & & \\
\hline CES3000000008 & Average Earnings Manufacturing & FRED & $\bullet$ & & $\bullet$ & & \\
\hline CPIAUCSL & CPI All Items & FRED & $\bullet$ & $\bullet$ & $\bullet$ & $\bullet$ & $\bullet$ \\
\hline PCEPI & PCE Deflator & FRED & $\bullet$ & & $\bullet$ & & $\bullet$ \\
\hline HOUST & Housing Starts & FRED & - & & $\bullet$ & & \\
\hline PERMIT & Building Permits & FRED & $\bullet$ & & $\bullet$ & & \\
\hline BUSINVx & Business Inventories & FRED & $\bullet$ & & $\bullet$ & & \\
\hline M2SL & M2 Money Stock & FRED & - & & $\bullet$ & & \\
\hline BUSLOANS & Business Loans & FRED & $\bullet$ & & $\bullet$ & & $\bullet$ \\
\hline DTCTHFNM & Consumer Loans & FRED & $\bullet$ & & $\bullet$ & & $\bullet$ \\
\hline RPI & Real Personal Income & FRED & $\bullet$ & & $\bullet$ & & \\
\hline DDURRA3M086SBEA & Real Consumption: Durable Goods & FRED & $\bullet$ & & $\bullet$ & & \\
\hline DNDGRA3M086SBEA & Real Consumption: Nondurable Goods & FRED & $\bullet$ & & $\bullet$ & & \\
\hline S\&P 500 & $\mathrm{~S} \& \mathrm{P} 500$ & FRED & $\bullet$ & & $\bullet$ & & $\bullet$ \\
\hline TB3MS & 3M T-Bill & FRED & & & & $\bullet$ & \\
\hline CRBPI & Commodity Price Index & CRB & $\bullet$ & $\bullet$ & $\bullet$ & & $\bullet$ \\
\hline EBP & GZ Excess Bond Premium & FRB & $\bullet$ & & $\bullet$ & $\bullet$ & $\bullet$ \\
\hline DGS1 & 1Y Treasury Rate & FRED & & & $\bullet$ & $\bullet$ & $\bullet$ \\
\hline DGS2 & 2Y Treasury Rate & FRED & & & & & $\bullet$ \\
\hline DGS5 & 5Y Treasury Rate & FRED & & & & & $\bullet$ \\
\hline DGS10 & 10Y Treasury Rate & FRED & & & & & $\bullet$ \\
\hline DGS20 & 20Y Treasury Rate & FRED & & & & & $\bullet$ \\
\hline YCSLOPE & Term (10Y-1Y Rate) Spread & FRED & & & $\bullet$ & & \\
\hline OECDEXP & Exports of Goods & OECD & $\bullet$ & & $\bullet$ & & \\
\hline OECDIMP & Imports of Goods & OECD & $\bullet$ & & $\bullet$ & & \\
\hline BISREER & Real Effective Exchange Rate & BIS & $\bullet$ & & $\bullet$ & & \\
\hline BASPREAD & BAA-AAA Spread & FRED & & & $\bullet$ & & \\
\hline MTGSPREAD & Mortgage Spread (10Y Treasury) & GK & & & $\bullet$ & & \\
\hline CSHPI & Case Shiller House Price Index & DATASTREAM & $\bullet$ & & $\bullet$ & & \\
\hline CFGDP & Expected Gross Domestic Product & $\mathrm{CE}$ & & & & $\bullet$ & \\
\hline CFPCE & Expected Personal Consumption & $\mathrm{CE}$ & & & & $\bullet$ & \\
\hline CFINV & Expected Business Investment & $\mathrm{CE}$ & & & & $\bullet$ & \\
\hline CFPROD & Expected Industrial Production & $\mathrm{CE}$ & & & & $\bullet$ & \\
\hline CFCPI & Expected Consumer Prices & $\mathrm{CE}$ & & & & $\bullet$ & \\
\hline CFURATE & Expected Unemployment Rate & $\mathrm{CE}$ & & & & $\bullet$ & \\
\hline CF3MRATE & Expected 3M Interest Rate & $\mathrm{CE}$ & & & & $\bullet$ & \\
\hline
\end{tabular}

Models: (1) Baseline set for tests in Sections 3 and 5; (2) Channels of monetary transmission in Figure 5; (3) Expectation channel in Figure 7; (4) Interest rate channel in Figure 6. Sources: Federal Reserve Economic Data (FRED), Commodity Research Bureau (CRB), Federal Reserve Board (RFB), Organisation for Economic Co-operation and Development (OECD), Bank for International Settlements (BIS), Gertler and Karadi (2015) (GK), Thomson Reuters (DATASTREAM), Consensus Economics $(\mathrm{CE})$. 
FiguRE C.1: INFORMATIONALLY-ROBUST INSTRUMENT FOR MONETARY POLICY SHOCKS: CRISIS EPISODES
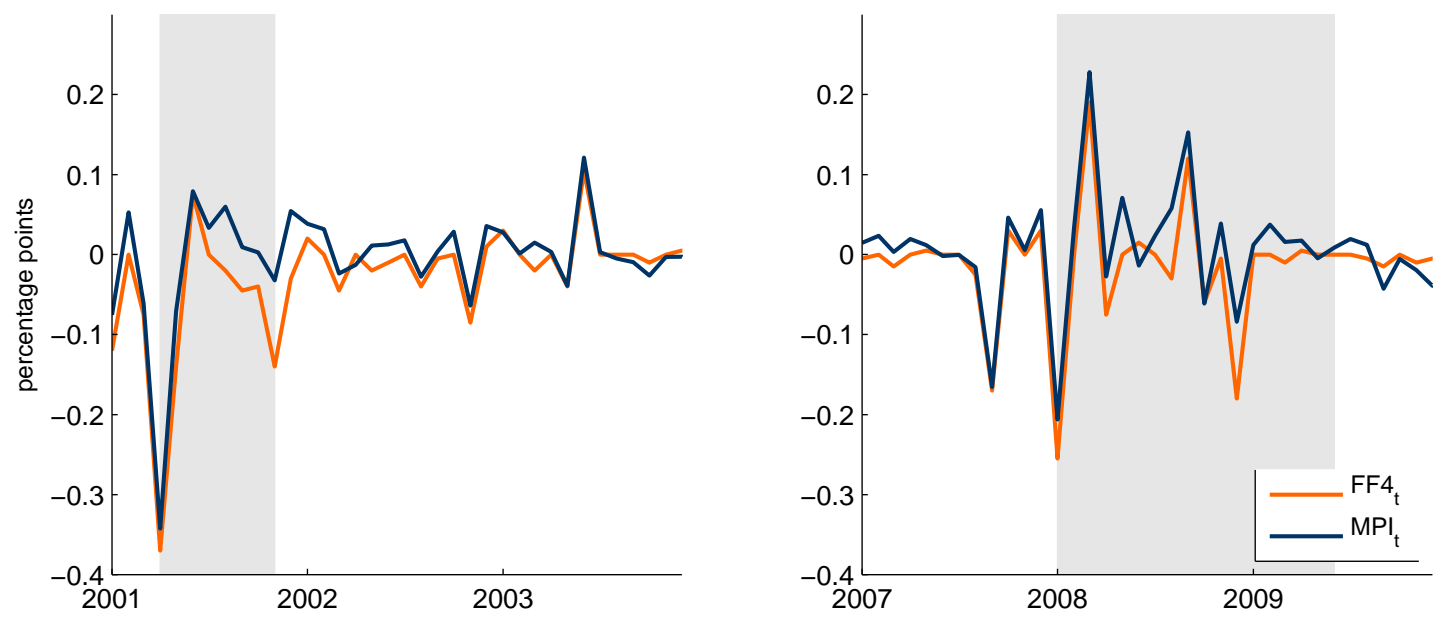

Note: market-based surprises conditional on private agents' information set $F F 4_{t}$ (orange line), residual to Eq. (1) $M P I_{t}$, (blue, solid). Shaded areas denote NBER recessions. LEFT PANEL: 2001:01 - 2003:12. RIGHT PANEL: 2007:01 - 2009:12.

Figure C.2: BlP Responses: Lag Length
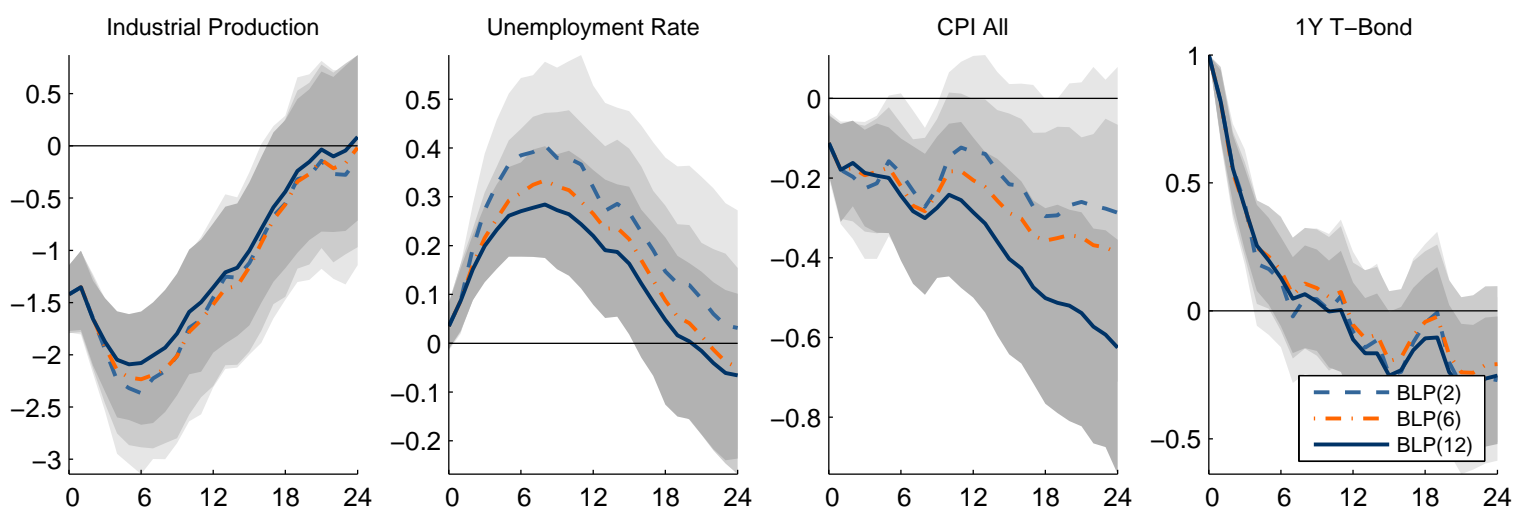

$B L P(2)$ (teal, dashed), $B L P(6)$ (orange, dash-dotted) and $B L P(12)$ (blue, solid) impulse responses. $V A R(12)$ prior. Shaded areas are $90 \%$ posterior coverage bands. 
Figure C.3: IRFs to Monetary Policy Shock: all Variables, All METHODS
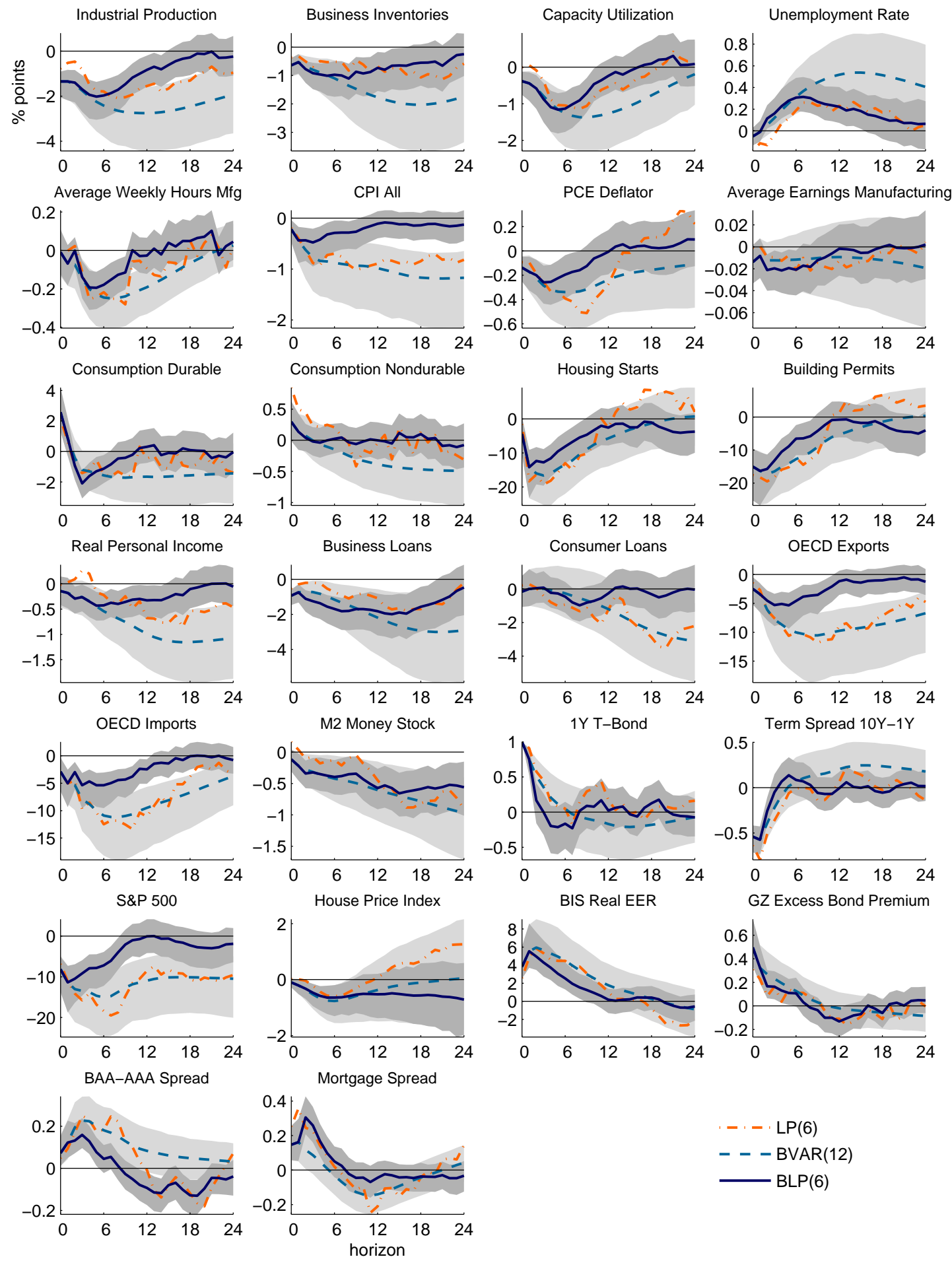

Note: BLP, VAR and LP responses to a contractionary monetary policy shock. Shock identified with the $M P I_{t}$ series and normalised to induce a 100 basis point increase in the 1-year rate. Sample 1979:01 2014:12. BLP(6) with $V A R(12)$ prior over 1969:01 - 1979:01. Shaded areas are 90\% posterior coverage bands. 
Figure C.4: IRFs to Monetary Policy Shock: Interest Rates, All MethodS
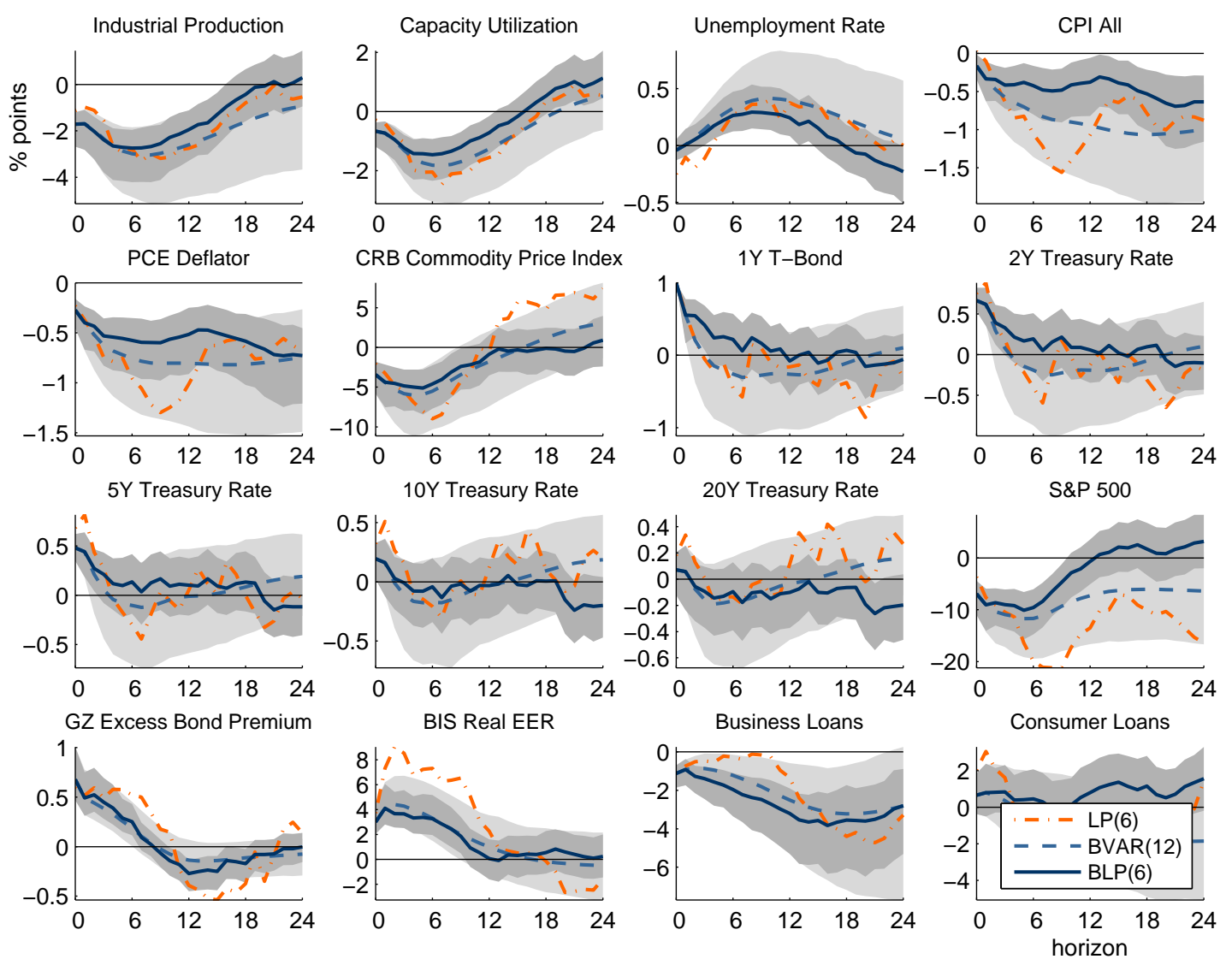

(A) Interest rates responses across horizons.
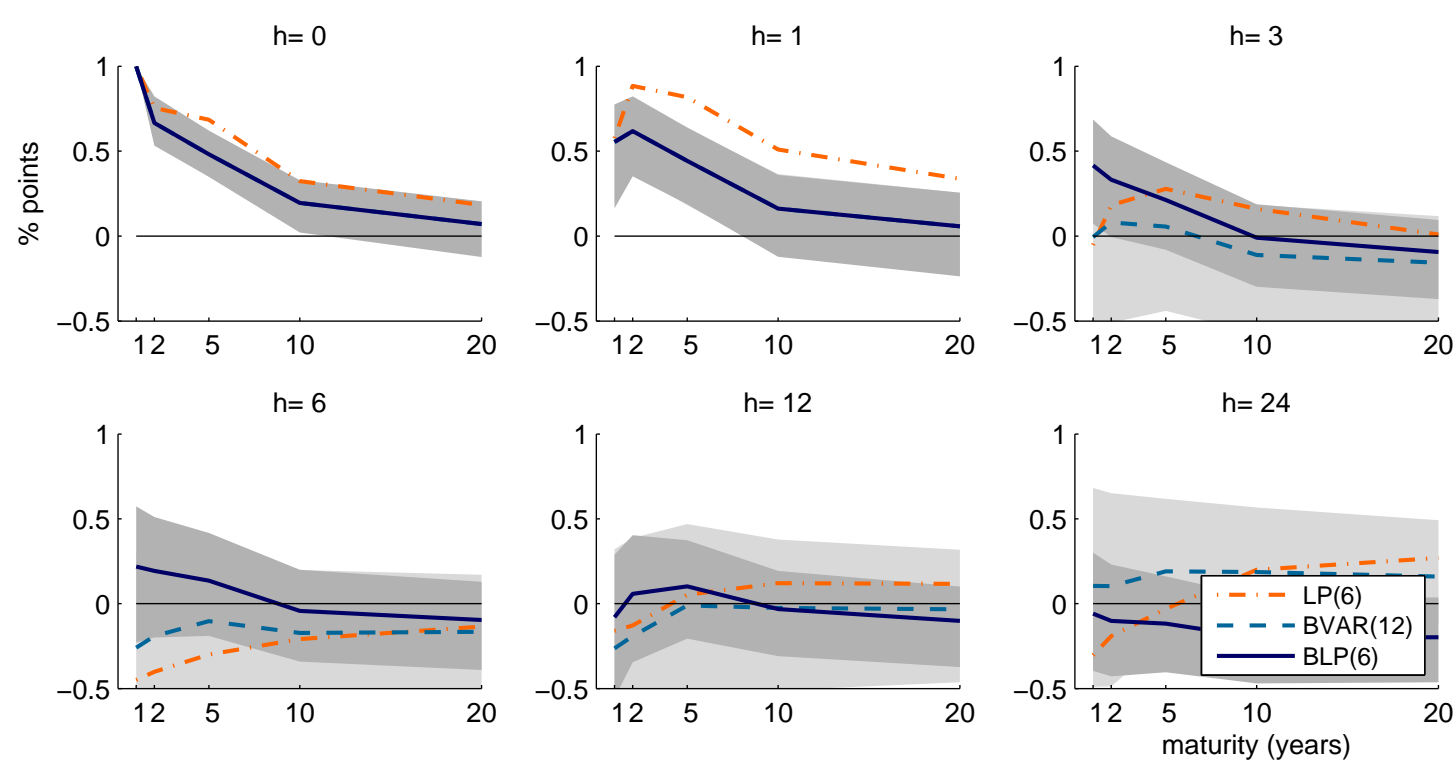

(в) Interest rates responses across maturities.

Note: BLP, VAR and LP responses to a contractionary monetary policy shock. Shock identified with the $M P I_{t}$ series and normalised to induce a 100 basis point increase in the 1-year rate. Sample 1979:01 - 2014:12. BLP(6) with $\operatorname{VAR}(12)$ prior ofer 1969:01 - 1979:01. Shaded areas are 90\% posterior coverage bands. 


\section{Figure C.5: IRFs to Monetary Policy Shock: Private Expectations, all Methods}
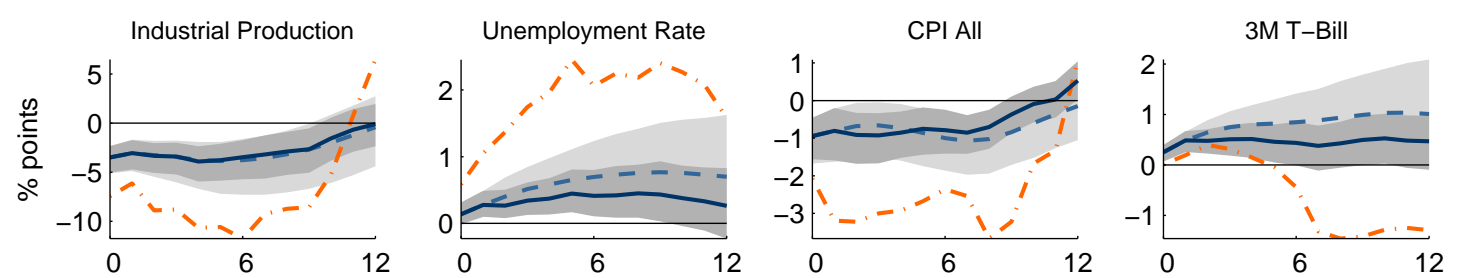

Consensus MEDIAN PROD
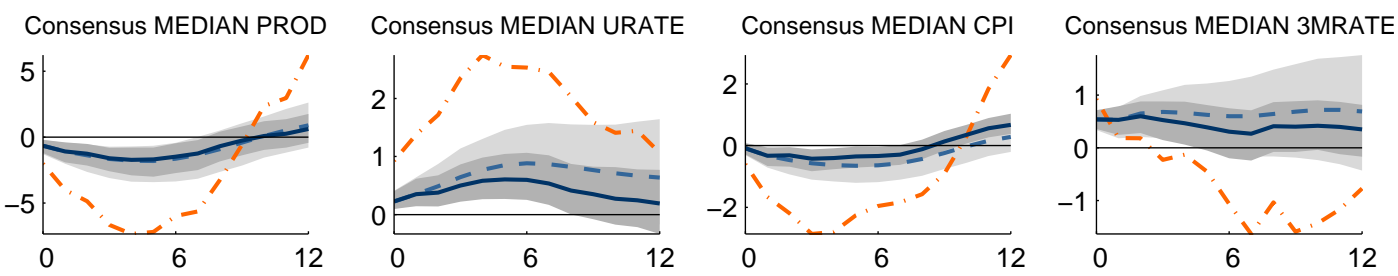

Consensus MEDIAN GDP
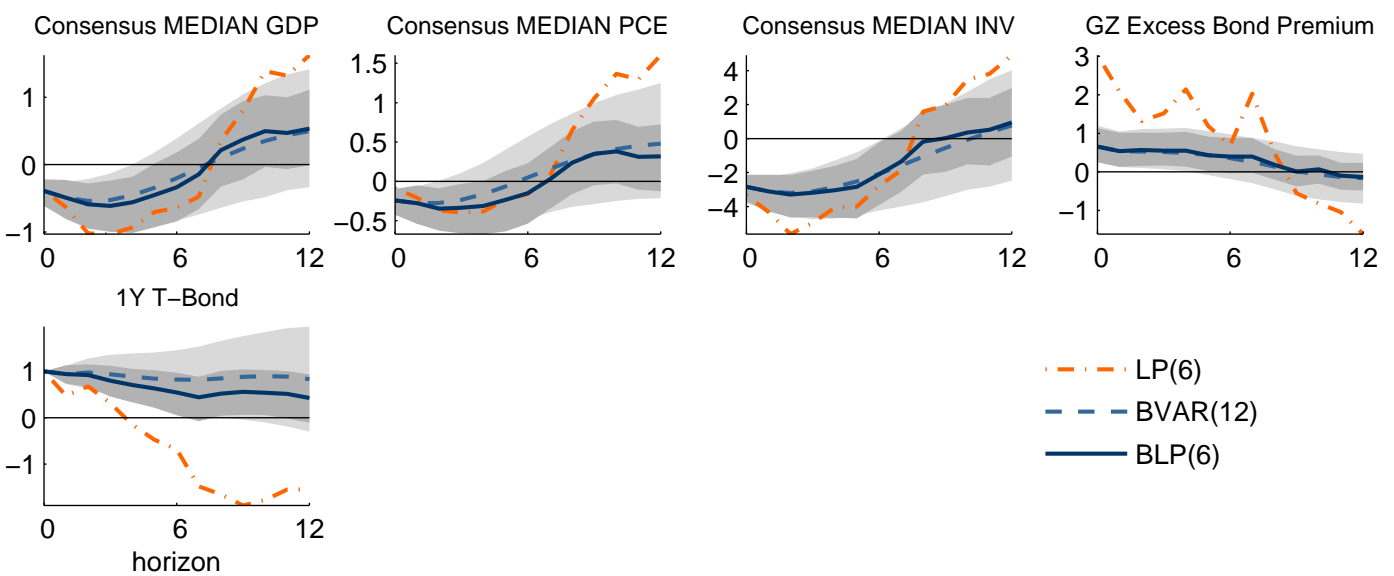

$-\cdot-\cdot \operatorname{LP}(6)$

- - - BVAR(12)

BLP(6)

Note: BLP, VAR and LP responses to a contractionary monetary policy shock. Shock identified with the $M P I_{t}$ series and normalised to induce a 100 basis point increase in the 1-year rate. Sample 1999:01 2014:12. BLP(6) with $V A R(12)$ prior over 1993:01 - 1999:01. Shaded areas are 90\% posterior coverage bands. 